Mariana Mari Ikoma

\title{
Caracterização de vesículas extracelulares liberadas por células de melanoma murino tratadas com quimioterápicos: possível papel modulador na sobrevivência das células tumorais?
}

\author{
Dissertação apresentada à Faculdade de \\ Medicina da Universidade de São Paulo \\ para obtenção do título de Mestre em \\ Ciências \\ Programa de Oncologia: \\ Orientadora: Profa. Dra. Andréia Hanada \\ Otake \\ Versão corrigida Resolução CoPGr 6018/11, de 13 de outubro de 2011.
}

São Paulo 
Mariana Mari Ikoma

\title{
Caracterização de vesículas extracelulares liberadas por células de melanoma murino tratadas com quimioterápicos: possível papel modulador na sobrevivência das células tumorais?
}

\author{
Dissertação apresentada à Faculdade de \\ Medicina da Universidade de São Paulo \\ para obtenção do título de Mestre em \\ Ciências \\ Programa de Oncologia: \\ Orientadora: Profa. Dra. Andréia Hanada \\ Otake
}

São Paulo 


\section{Dados Internacionais de Catalogação na Publicação (CIP)}

Preparada pela Biblioteca da

Faculdade de Medicina da Universidade de São Paulo

Creprodução autorizada pelo autor

\section{Ikoma, Mariana Mari}

Caracterização de vesículas extracelulares liberadas por células de melanoma murino tratadas com quimioterápicos: possível papel modulador na sobrevivência das células tumorais? / Mariana Mari lkoma. -- São Paulo, 2017.

Dissertação(mestrado)--Faculdade de Medicina da Universidade de São Paulo. Programa de Oncologia.

Orientadora:Andréia Hanada Otake.

Descritores: 1.Vesículas extracelulares 2.Melanoma 3.Neoplasias cutâneas 4.Cisplatino 5.Tratamento farmacológico 6.Morte celular 


\section{AGRADECIMENTOS}

Agradeço a Profa. Dra. Andréia $\mathrm{H}$ Otake, que me orientou com paciência e franqueza. Ao Prof. Dr. Roger Chammas, pela oportunidade e discussões dos resultados. Aos pesquisadores do grupo, Luciana, Tharcísio, Renata, Tatiana e Silvina, por todas as técnicas que aprendi nesses anos de mestrado. Aos amigos que conquistei no laboratório, Flávia, Karina, Silvia, Priscila, Camila MM, Adalberto, Mayara e Mauro, que ouviram todas as minhas lamentações. Aos colegas e técnicos do CTO, obrigada por abrirem as portas de vidro quando meu crachá não funcionava.

Agradeço ao grupo de Biologia Celular e Molecular do Centro Internacional de Pesquisa do hospital AC Camargo, principalmente a Dra Vilma pela parceria, e aos doutores Antuani e Gabriela, por disponibilizar seus tempos para analisar as vesículas extracelulares no nanosigth, além das discussões sobre o andamento da pesquisa em vesículas extracelulares no cenário global.

Agradeço a Mara do Centro de Medicina Nuclear, por todos os experimentos in vivo que realizei.

A pós-graduação em oncologia da Faculdade de Medicina da USP, principalmente as secretárias Yara e Débora, por auxiliarem e facilitarem as burocracias.

A CAPES pelo apoio financeiro.

Aos citados e todos os demais, obrigada por tudo. 
Sumário

Lista de figuras

Lista de siglas

Lista de abreviaturas

Resumo

Abistract

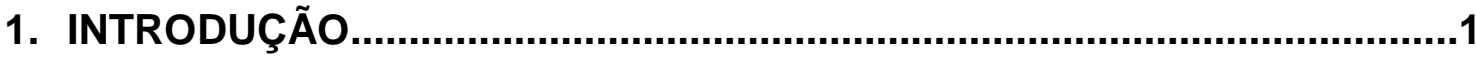

1.1 Melanoma

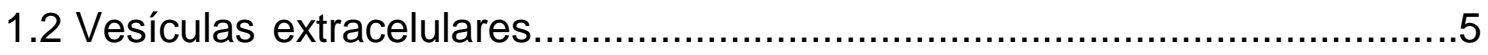

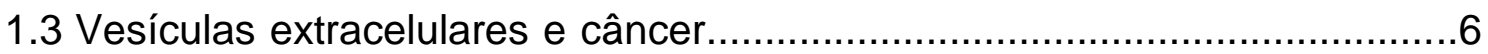

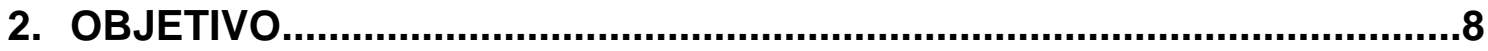

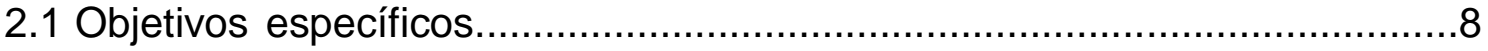

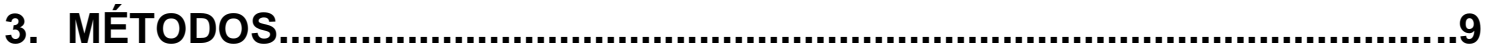

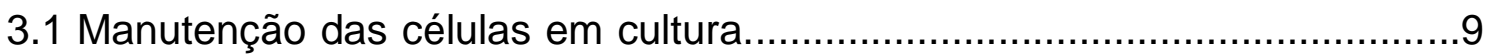

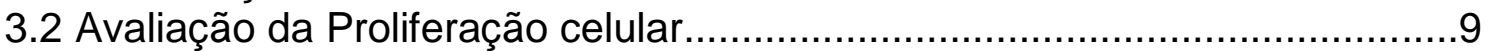

3.3 Depleção das vesículas extracelulares do soro fetal bovino..........................

3.4 Avaliação da toxicidade das drogas......................................................10

3.4.1 Viabilidade celular.................................................................... 10

3.4.2 Ensaio de clonogenicidade.........................................................

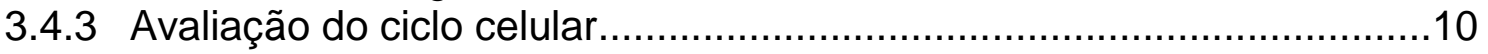

3.5 Isolamento de vesículas extracelulares..............................................11

3.6 Quantificação das vesículas extracelulares.............................................12

3.7 Avaliação da Incorporação das vesículas extracelulares...........................13

3.8 Avaliação de crescimento tumoral in vitro.............................................14

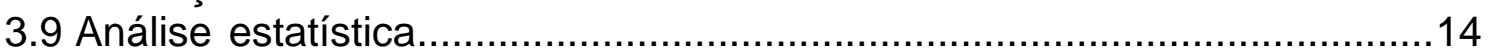

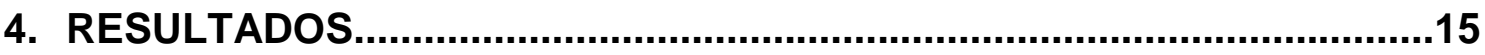

4.1 Padronização das condições de cultura celular para geração de vesículas extracelulares. . .15

4.1.1 Determinação da concentração das drogas CDDP e TMZ ....................16

4.1.2 Toxicidade da CDDP............................................................17

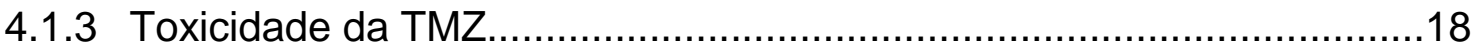

4.1.4 Otimização de tratamento com TMZ ………..................................20

4.1.5 Padronização da quantificação de VEs..................................22

4.1.6 Padronização da marcação de VEs...................................................24

4.2 Análise do perfil diferencial de VEs obtidas por diferentes tratamentos....25

4.3 Análise das respostas celulares conferidos por VEs resultantes de

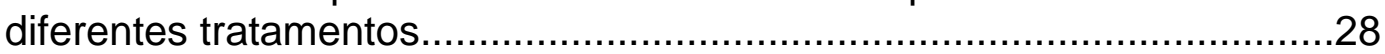

4.3.1 Avaliação da atividade de VEs oriundas de células tratadas com CDDP ou TMZ em B16-F10 ...............................................................28

4.3.2 Avaliação da atividade de VEs oriundas de células tratadas com CDDP ou TMZ em células tumorais in vivo...................................................30

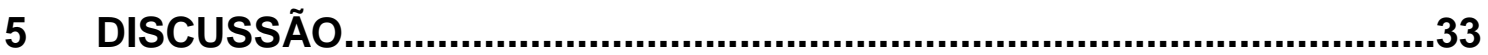

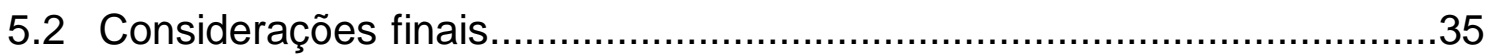

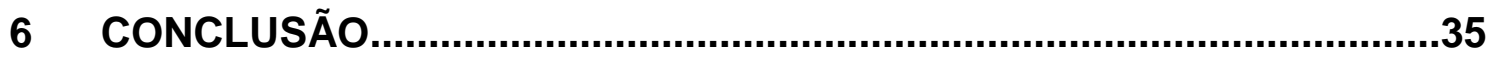

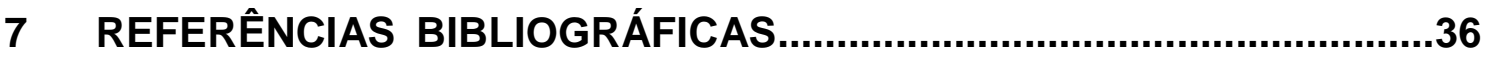




\section{LISTA DE FIGURAS}

Figura 1 - Esquematização da progressãodos melanomas...........................1

Figura 2 - Mecanismo de ação da CDDP..................................................

Figura 3 - Mecanismo de ação da TMZ .......................................................

Figura 4 - Classificação das VEs de acordo com o diâmetro............................

Figura 5 - Processo de centrifugações para isolar as VEs...........................11

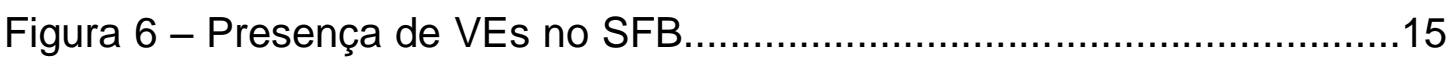

Figura 7 - Padronização da obtenção de VEs.............................................16

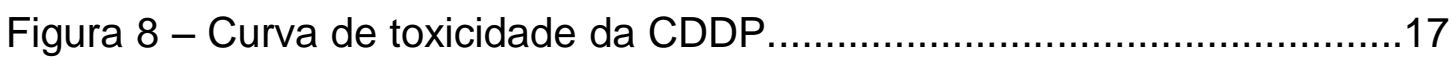

Figura 9 - Curva de citotoxicidade da TMZ ............................................19

Figura 10 - Protocolo de tratamento com TMZ .......................................20

Figura 11 - Otimização do tratamento com TMZ ......................................21

Figura 12 - Otimização do tratamento com reforço da TMZ..........................22

Figura 13 - Padronização da quantificação de VEs.........................................23

Figura 14 - Padronização da marcação de VEs..........................................24

Figura 15 - Quantificação e análise de rastreamento de partículas de VEs oriundas de células tratadas com CDDP e TMZ .........................................26

Figura 16 - Quantificação de VEs liberadas por células................................27

Figura 17 - Resposta celular após o tratamento com VEs.............................28

Figura 18 - Resposta celular após o tratamento com VEs..............................30

Figura 19 - Atividade das VEs oriundas de células tratadas com CDDP ou TMZ sobre as células tumorais................................................................. 


\section{LISTA DE SIGLAS}

\begin{tabular}{|c|c|}
\hline APS & Perssulfato de amônio \\
\hline BSA & Albumina do soro bovino \\
\hline CDDP & cis-diaminodicloroplatina II - cisplatina \\
\hline $\mathrm{dH}_{2} \mathrm{O}$ & Água destilada \\
\hline $\mathrm{DiO}$ & dialkylcarbocyanines \\
\hline DMSO & dimetilsulfóxido \\
\hline DNA & Ácido desoxi ribonucleico \\
\hline DU145 & Linhagem celular de câncer de próstata humano \\
\hline EDTA & Ácido etilenodiamino tetra-acético \\
\hline G0G1 & Gap 0 Gap 1 \\
\hline IFN & Interferon \\
\hline $\mathrm{IL}-2$ & Interleucina2 \\
\hline INCA & Instituto Nacional de Câncer \\
\hline MGMT & Metil guanina-metil transferase \\
\hline MMR & mismatchrepair \\
\hline MTIC & 5-(3-metiltriazen-1-il) imidazole-4-carboxamida \\
\hline MTT & Sal de tetrazolium \\
\hline N3 & 3№ Nitrogênio \\
\hline N7 & 7ํ№ Nitrogênio \\
\hline PBS & Tampão fosfato-salino \\
\hline PARP & poly(ADP-ribose) polymerase \\
\hline $\mathrm{Pl}$ & lodeto de propídeo \\
\hline PMSF & Phenylmethanesulfonylfluoride \\
\hline PrECs & Linhagem celular de câncer de próstata humano \\
\hline RNA & Ácido ribonucleico \\
\hline RPMI & Meio de cultura Roswell Park Memorial Institute \\
\hline SDS & Sodiumdodecyl sulfate \\
\hline SFB & Soro fetal de bovino \\
\hline SG2M & Síntese Gap 2 Mitose \\
\hline TEMED & $\mathrm{N}, \mathrm{N}, \mathrm{N}^{\prime}, \mathrm{N}^{\prime}$-Tetrametiletilenodiamino \\
\hline
\end{tabular}


3-methyl-[triazen-1-yl]-imidazole-4-carboxamide (Temozolomida)

Tris

Trisaminometano

UK

Reino Unido

USA

Estados Unidos da América

VEs

Vesículas extracelulares 


\section{LISTA DE ABREVIATURAS}

\begin{tabular}{ll}
$\mu \mathrm{g} / \mathrm{mL}$ & Microgramas por mililitros \\
$\mu \mathrm{L}$ & Microlitros \\
$\mu \mathrm{m}$ & Micrômetros \\
$\mathrm{C} f$ & Concentração final \\
$\mathrm{cm}$ & Centímetros \\
$\mathrm{cm}^{2}$ & Centímetros quadrados \\
$\mathrm{CO}_{2}$ & Dióxido de carbono \\
et al & E colaboradores \\
$\mathrm{g}$ & Gravidade \\
$\mathrm{microRNAs}$ & Micro RNA \\
$\mathrm{mM}$ & Milimols \\
$\mathrm{mRNA}$ & RNA mensageiro \\
$\mathrm{nm}$ & Nanômetros \\
oC & Graus célsius \\
$\mathrm{p}$ & Probabilidade de significância \\
$\mathrm{pH}$ & Potencial hidrogeniônico \\
$\mathrm{R} 10$ & Meio de cultura suplementado com 10 \% de SFB \\
SA $\beta$-Gal & Beta-galactosidase associada à senescência \\
SFBd & Soro fetal bovino depletado de vesícula extracelular \\
v & Volt \\
VE CDDP & Vesícula extracelular oriunda de células tratadas com cisplatina \\
VE DMSO & Vesícula extracelular oriunda de células tratadas com \\
VE PBS & dimetilsulfóxido \\
VE TMZ & Vesícula extracelular oriunda de células tratadas com Tampão \\
& fosfato-salino \\
\hline Vesícula extracelular oriunda de células tratadas com \\
temozolomida \\
\hline
\end{tabular}




\section{RESUMO}

O Melanoma é um tipo de neoplasia que se origina de melanócitos normalmente presentes na epiderme. Uma das características do melanoma é a capacidade de adquirir resistência a terapias. As células de melanoma podem aumentar a liberação de vesículas extracelulares (VEs) em resposta ao tratamento com quimioterápicos. A cisplatina (CDDP) e a temozolomida (TMZ) são drogas utilizadas para o tratamento de tumores. Ambas as drogas formam adutos no DNA, mas as vias de sinalização que deflagram a morte celular são distintas. $O$ objetivo desse estudo é investigar a morte celular da linhagem B16-F10 na presença de VEs oriundas de células B16-F10 tratadas com cisplatina CDDP ou TMZ. Inicialmente as VEs oriundas de células de melanoma murino, B16-F10, tratadas com CDDP ou TMZ e seus controles, foram isoladas por ultracentrifugações sucessivas. Para os experimentos in vitro, as células foram tratadas com as drogas em combinação com as respectivas VEs. As amostras foram realizados avaliações de ciclo celular e de morte e ensaio clonogênico. Para os experimentos in vivo, as células B16-F10 foram pré-tratadas com VEs, e posteriormente, as células foram inoculadas via subcutânea em camundongos C57BL/6 e os tumores foram mensurados diariamente. Em nosso estudo concluimos que a metodologia do isolamento de VEs é eficiente. Além disso, observamos que o tratamento com CDDP ou TMZ aumenta a liberação de VEs por células tumorais. Apesar do resultado contraditorio, as VEs liberadas por células tumorais tratadas com quimioterápicos aumentam a capacidade de sobrevivência das células de melanoma in vitro. VEs oriundas de células de melanoma não participam inicialmente da sensibilização à morte de células tumorais causada pelas mesmas drogas, mas a longo prazo, as VEs oriundas de células tratadas com a TMZ podem conferir uma resposta celular de sobrevivência às células tumorais in vitro. In vivo, o resultado é inconclusivo, uma vez que para confirmar se as VEs fazem parte da adaptação tumoral conferindo fenômenos de sobrevivência celular in vivo, é necessário avaliar em outros modelos celulares e animais.

Ikoma MM. Caracterização de vesículas extracelulares liberadas por células de melanoma murino tratadas com quimioterápicos: possível papel modulador na sobrevivência das células tumorais? [Dissertação]. São Paulo: Faculdade de Medicina, Universidade São Paulo; 2017. 


\section{ABSTRACT}

Melanoma is a neoplasm derived from melanocytes normally present in the skin specifically in the epidermis. One of the malignancies of melanoma is the ability to acquire chemoresistance. Cisplatin (CDDP) and temozolomide (TMZ) are drugs used for the treatment of tumors. Both drugs can form alkylating adducts in DNA, however, the pathways that trigger cell death are distinct. Tumor cells, including melanoma, may increase the release of extracellular vesicles (EVs) in response to chemotherapeutic treatment. The aim of this study is to investigate the cell death phenomenon in B16-F10 cell line in presence of EVs derived from chemotherapeutic-treated B16-F10 cells. For in vitro experiments, the cells were treated with CDDP or TMZ in combination with EVs from chemotherapictreated samples. For in vivo experiments, B16-F10 cells were exposed to EVs and inoculated subcutaneously in C57BL/6 mice. The growth was measured daily. In this work, we established and characterized VEs released by melanoma cells treated with chemotherapics and we established chemotherapics treatments to isolate EVs for next EVs isolation. Our results showed that CDDP or TMZ treatment increase the release of EVs by tumor cells. The EVs released by melanoma cells after CDDP or TMZ treatment seem to increase the survival capacity of melanoma cells. Thus, we concluded that EVs derived from melanoma cells do not participate in the cell death sensitization induced by CDDP or TMZ. However, EVs derived from TMZ treated cells may offer a survival effect to tumor cells in vitro a long term. In vivo, The result is inconclusive since to confirm how VEs are part of the tumor adaptation conferring cellular survival phenomena in vivo, it is necessary to evaluate in other cellular and animal models.

Ikoma MM. Characterization of extracellular vesicles released by murine melanoma cells treated with chemotherapeutic agents: a possible modulating role in cell survival? [Dissertation]. São Paulo: "Faculdade de Medicina, Universidade São Paulo"; 2017. 


\section{Introdução}

\subsection{Melanoma}

Melanoma é uma neoplasia que se origina de melanócitos normalmente presentes na epiderme e, algumas vezes, na derme. Surge predominantemente na pele (melanoma cutâneo) podendo originar-se em outros locais como superfície da mucosa oral e anogenital, esôfago, meninges e olhos. Os fatores de risco estão relacionados principalmente à predisposição genética (melanoma familial) e exposição à radiação solar (melanoma esporádico) [Bertolotto C. 2013]. O Instituto Nacional de Câncer (INCA) estimou que ocorreram 5.670 novos casos em 2016, sendo 3.000 homens e 2.670 mulheres. O melanoma representa $4 \%$ das neoplasias malignas de pele, e possui maior mortalidade em relação aos outros subtipos de câncer de pele, devido à alta capacidade metastática [INCA 2017], podendo evoluir de lesão cutânea localizada a tumor agressivo que, com o tempo, geram metástases e adquirem resistência a terapias [Bertolotto C. 2013].

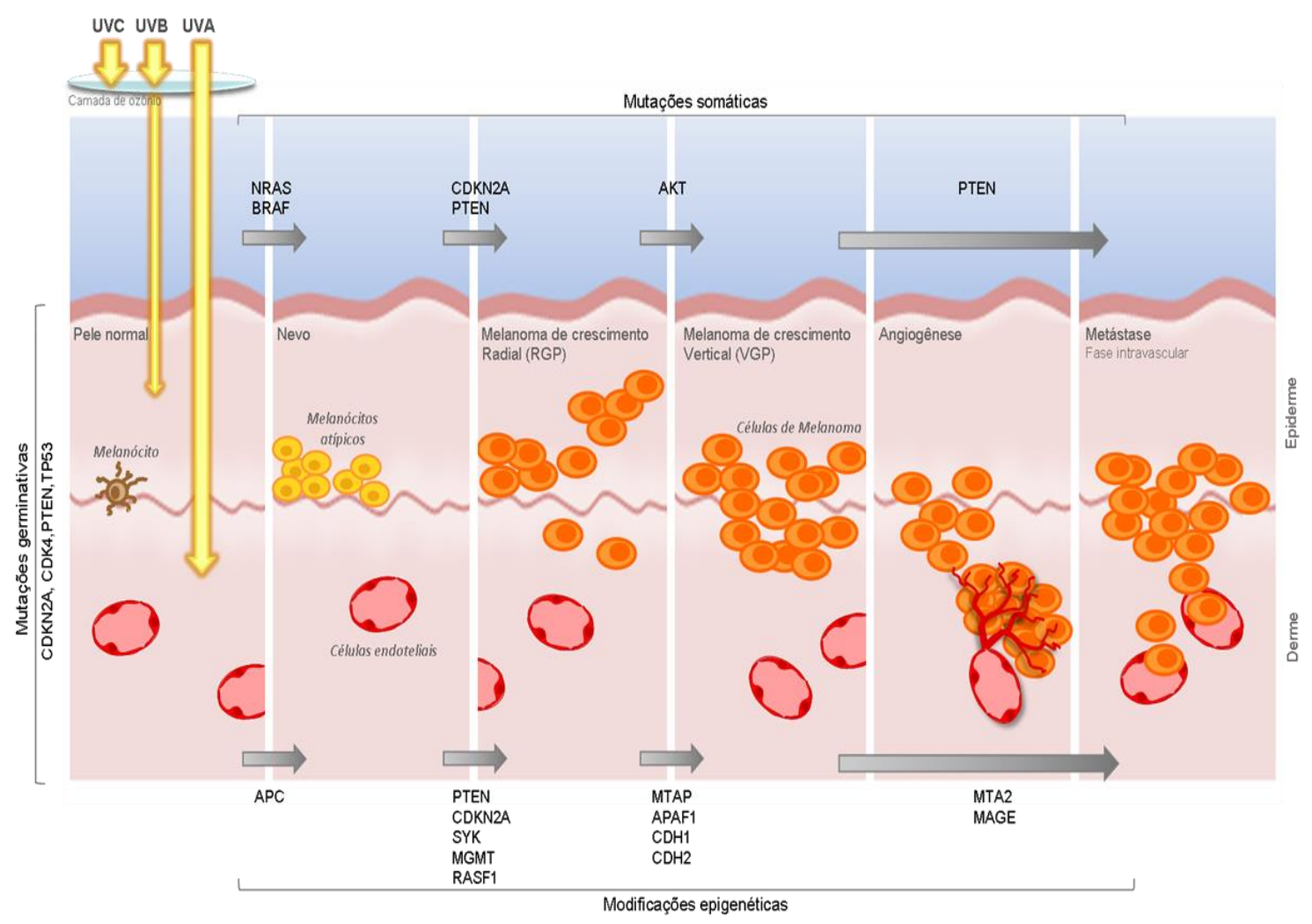

Figura 1: Esquematização da progressão do melanoma. Figura retirada de Francisco $\mathrm{G}$ et al (2013) [Francisco $\mathrm{G}$ et al, 2013] 
A progressão do melanoma pode ser descrita por diferentes etapas (Figura 1). Inicialmente, um nevo atípico constituído por uma população clonal de melanócitos proliferantes de forma aberrante pode modificar-se em uma lesão hiperplásica, mas não evolui devido à senescência celular. Uma vez que ocorre perda da senescência, a displasia do nevo pode progredir para uma fase de crescimento radial que está confinada à epiderme e possui um baixo potencial invasivo. Finalmente, as células de melanoma adquirem a capacidade de invadir a derme, passando para fase de crescimento vertical e metástases. Essas modificações podem ocorrer de forma não linear, podendo haver supressão de alguns passos, de modo que um melanoma na fase de crescimento radial pode evoluir diretamente para um melanoma metastático [Zaidi MR et al, 2008].

Em 2013, o ministério da saúde publicou a diretriz para o diagnóstico e tratamento do melanoma cutâneo. A diretriz orienta que os quimioterápicos recomendados para o tratamento do melanoma são a cisplatina, dacarbazina, vimblastina, IL-2 (interleucina 2) e IFN (interferon). No Brasil, a dacarbazina é o quimioterápico mais amplamente utilizado no tratamento de melanoma metastático [Ministério da Saúde, PORTARIA № 357, DE 8 DE ABRIL DE 2013].

Em nosso estudo, utilizamos a cisplatina (cis-diaminodicloroplatina II ou CDDP) e a temozolomida (3-methyl-[triazen-1-yl]-imidazole-4-carboxamide ou TMZ). A CDDP apresenta uma resposta modesta no tratamento do melanoma metastático e a TMZ por ser análoga à dacarbazina, droga amplamente utilizada no tratamento do melanoma, no entanto, a dacarbazina necessita de metabolização hepática [Bajetta E et al, 2002; Bhatia $S$ et al, 2009], e em nossos experimentos utilizamos a cultura de células tumorais.

A CDDP age formando adutos de DNA, os quais ativam processos celulares que estão envolvidos na: 1) regulação da sinalização de danos no DNA; 2) checkpoints de controle do ciclo celular; e 3) reparo do DNA, promovendo assim, morte celular por apoptose e necrose [Wang D e Lippard SJ 2005.]. Seu mecanismo de ação envolve a interposição de pontes cruzadas entre nucleotídeos de DNA, na mesma hélice ou em hélices complementares. Além disso, a cisplatina liga-se ao RNA e a proteínas celulares e promove também estresse oxidativo [Mandic A et al, 2003]. 
A esquema a baixo (Figura 2) mostra o mecanismo de ação da CDDP. 0 mecanismo de morte celular induzido por CDDP depende da concentração em que a célula é exposta à droga. A apoptose resulta da ativação da caspase por mecanismos de deteç̧ão de dano ao DNA. As características morfológicas das células que sofrem apoptose incluem a diminuição no diâmetro celular, a condensação da cromatina e a fragmentação do DNA. Por outro lado, a necrose deflagrada por CDDP inicia-se pelo aumento citosólico e perda precoce da integridade da membrana plasmática [Wang D e Lippard SJ 2005].

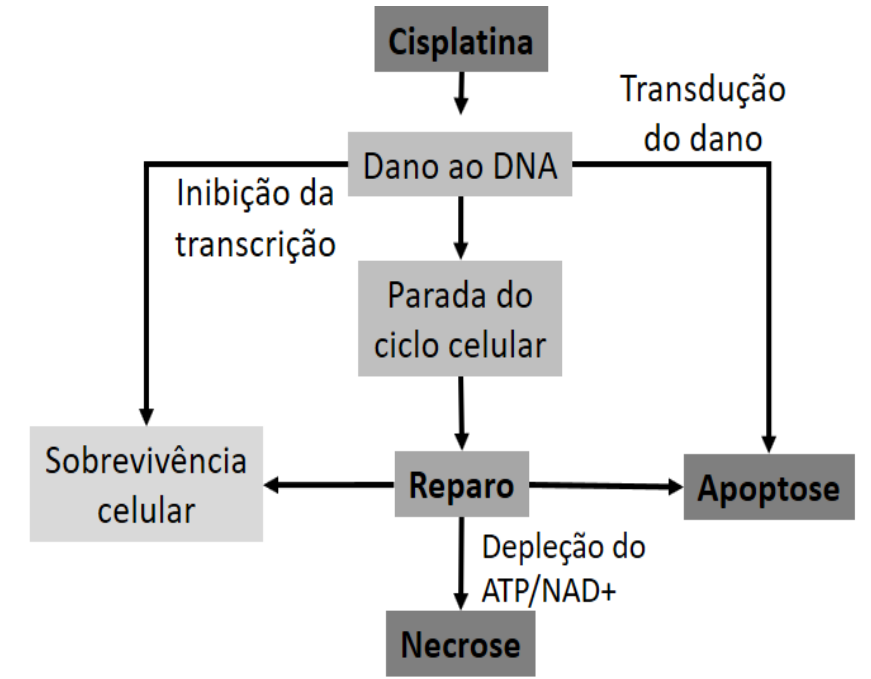

Figura 2: Mecanismos de ação da CDDP. Figura adaptada de Wang e Lippard (2005)

A TMZ também forma adutos citotóxicos, metilando o DNA na posição O6 da guanina. A representação esquemática abaixo (Figura 3) mostra o mecanismo de ação da TMZ. O mecanismo de ação inicia-se pela conversão química, não-enzimática, da TMZ para o metabólito 5-(3-metiltriazen-1-il) imidazole-4-carboxamida (MTIC). As lesões de DNA causadas pelo MITC são: 1) a metilação na posição $N 7$ da guanina; 2) a metilação na posição $N 3$ da adenina; e 3) a metilação na posição 06 da guanina. A metilação da posição N7 da guanina, assim como da posição N3 da adenina, é reparada pela enzima PARP e não são citotóxicas [Thomas $A$ et al, 2013].

A metilação da guanina é a mais crítica para a citotoxicidade da TMZ. Os mecanismos de reparo da metilação da guanina são possibilitados pela ação da enzima metil guanina metil transferase (MGMT), que remove o aduto de metil da guanina, ou a ativação da via de reparo por incompatibilidade de bases nitrogenadas (MMR do inglês mismatchrepair), os quais podem levar à 
sobrevivência de células tumorais. Quando a remoção do metil não é eficiente, ou a vida MMR não é ativada, pode ativar a via de morte celular, deflagrando assim, a apoptose celular [Thomas A et al, 2013; Fan CH et al, 2013], ou senescência celular [Mhaidat NM et al, 2007].

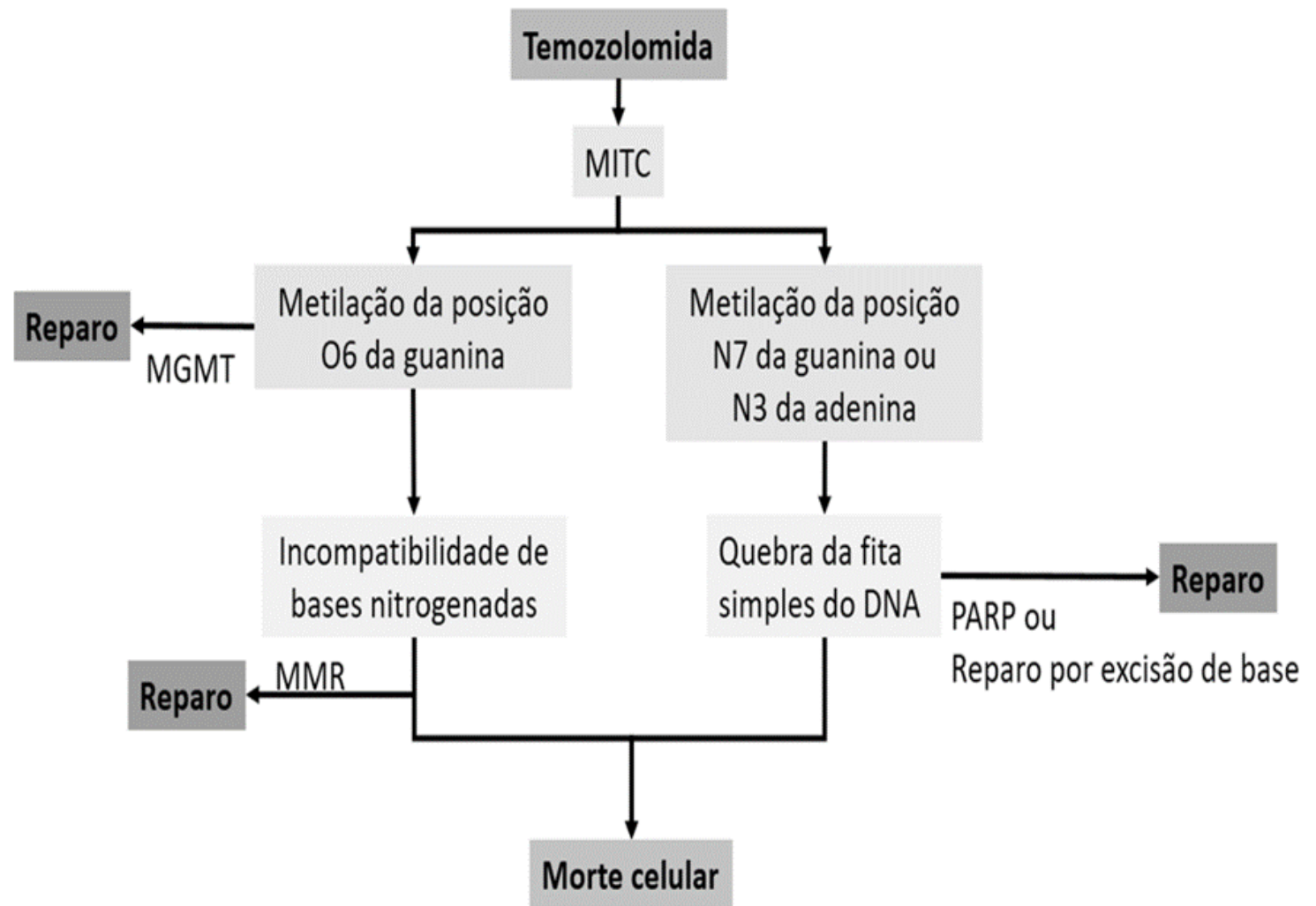

Figura 3: Mecanismo de ação da TMZ. Figura adaptada de Anish Thomas et al (2017).

A eficácia da quimioterapia do câncer é muitas vezes prejudicada por um fenômeno chamado de resistência a múltiplas drogas, uma característica intrínseca ou adquirida do tumor. Essa resistência pode ser resultado de vários mecanismos distintos, tais como alterações nos checkpoints do ciclo celular, comprometimento das vias de apoptose, reparo de danos do material genético e redução do acúmulo de drogas intracelular [La Porta CA, 2009]. Outro mecanismo de resistência à droga é a liberação de vesículas extracelulares (VEs), no qual a célula libera estruturas esféricas de membrana celular, contendo a droga, para o meio extracelular [Federici $C$ et al, 2014]. Ainda não se sabe se a CDDP ou a TMZ, que desencadeiam mecanismos de morte celular, podem alterar o perfil de vesículas extracelulares liberadas por células de melanoma. 


\subsection{Vesículas extracelulares}

As VEs são fragmentos liberados da membrana plasmática de células que se originam através de pelo menos três mecanismos distintos: 1) Os corpúsculos apoptóticos que são liberados durante o processo de morte celular; 2) os exossomos que são liberados constitutivamente por células e; 3) as microvesículas que são liberadas durante a formação de blebbing da membrana plasmática em condições de estresse celular [György B et al, 2011].

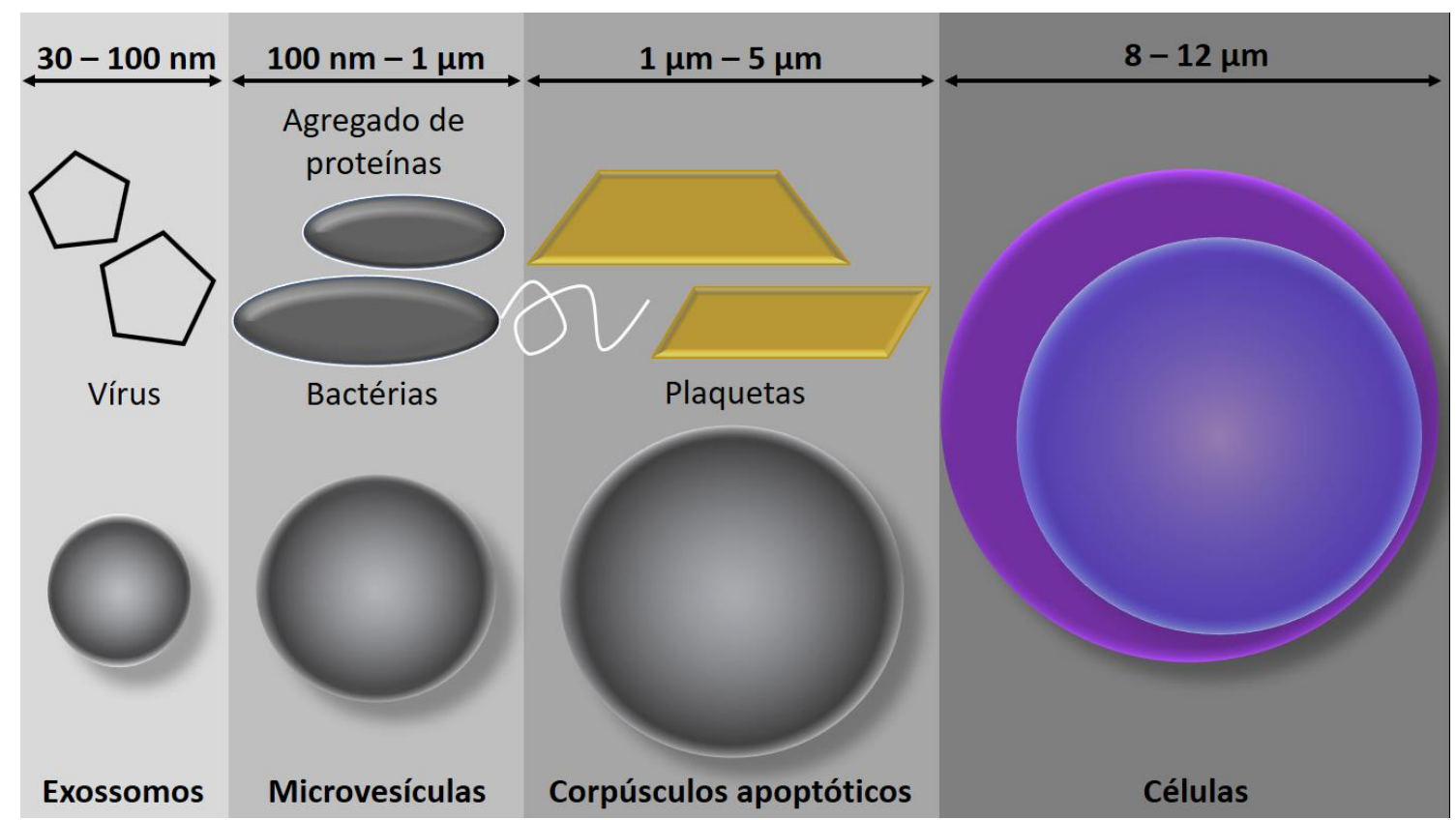

Figura 4: Classificação das VEs de acordo com o diâmetro. Figura adaptada de György et al. (2011)

As características estabelecidas para as VEs, independentemente da sua origem celular, incluem o seu tamanho, sendo os exossomos entre $30 \mathrm{~nm}$ a $100 \mathrm{~nm}$ de diâmetro; sendo as microvesículas de $100 \mathrm{~nm}$ a $1 \mu \mathrm{m}$; e os corpúsculos apoptóticos de $1 \mu \mathrm{m}$ a $5 \mu \mathrm{m}$. Em seu interior podem carregar componentes citoplasmáticos, tais como proteínas e enzimas do citoesqueleto; citocinas e receptores específicos dependendo do tipo de estímulo ou da origem celular; e também podem conter RNAs (mRNA e microRNAs) [György B et al, 2011].

Os estudos sobre VEs iniciaram em 1956, com o médico Don W. Fawcett, que observou, através da microscopia eletrônica, estruturas esféricas no meio intra e extracelulares [Fawcett DW. 1956]. Em 1969, as estruturas 
foram associadas à entrada de vírus e posterior liberação pelas células infectadas [Dunnebacke TH et al, 1969].

As VEs foram categorizadas inicialmente pelo seu tamanho em diâmetros. Mais tarde, com a evolução de técnicas como microscopia confocal, citometria de fluxo e estudos moleculares, as VEs foram categorizadas de acordo com o mecanismo em que foram geradas [György B et al, 2011]. Atualmente, equipamentos como Exoscreen e Nanosigth estão sendo utilizados para quantificar com maior precisão e categorizar de acordo com as moléculas que essas estruturas carregam.

\subsection{Vesículas extracelulares e câncer}

Nos microambientes tumorais as células são desafiadas constantemente por processos químicos ou em diversas condições de estresse físico, que levam à liberação de VEs [Inal JM et al, 2012]. A sua diversidade estrutural e ação biológica podem estar associadas à diferenciação celular [Fader CM et al, 2012], estresse oxidativo [Hedlund $M$ et al, 2011] ou apoptose [Sarkar $A$ et al, 2009]. A atividade biológica das VEs na transformação maligna do tumor está associada ao mecanismo de apoptose [Munoz JL et al, 2013], escape da vigilância do sistema imune [Marton A et al, 2012], angiogênese [Kawamoto T et al, 2012] e metástase [Hood JL et al, 2011].

As VEs oriundas de células tumorais transportam partículas como DNA, RNA, mRNA e microRNA [Panagopoulos $K$ et al, 2013] e em funções imunológicas [deVrij $J$ et al, 2015]. Essas VEs são constitutivamente liberadas e podem servir como veículo para vários determinantes na progressão do tumor, transportando partículas de células tumorais para outras células do microambiente [Baj-Krzyworzeka $\mathrm{M}$ et al, 2006].

As células tumorais podem aumentar a liberação de VEs como resposta a quimioterapia [Lv LH et al, 2012; Federici C et al, 2014], além de transferir fenótipos de resistência [26]. As VEs também atuam sobre linfócitos natural killer [Lv LH et al, 2012], monócitos [Baj-Krzyworzeka M et al, 2011] e macrófagos [Van der Vos KE et al, 2016], mas o seu efeito sobre as células tumorais não está totalmente elucidado.

A descrição de VEs no melanoma iniciou-se com Sloane et al (1986), que associou a liberação de fragmentos da membrana plasmática com 0 
aumento da capacidade metastática de células das linhagens B16 de melanoma murino [Sloane BF et al, 1986]. Contudo, os estudos sobre a atuação dessas VEs no tumor ainda são pouco explorados.

Devido à diversidade de mecanismos celulares para sobrevivência apresentada em células tumorais, os processos envolvidos na comunicação celular e transferência de informações entre as células tumorais para 0 aumento da resistência a morte precisa ser melhor investigado. Assim, o presente estudo visa compreender melhor a transferência de moléculas entre as células tumorais mediadas por vesículas extracelulares. 


\section{OBJETIVO}

Avaliar a resposta celular após o tratamento com vesículas extracelulares liberadas por células de melanoma murino tratadas com quimioterápicos.

\subsection{Objetivos específicos}

1 - Padronização do método de isolamento de vesículas extracelulares liberadas por células de melanoma murino in vitro.

2 - Padronização das condições de tratamentos com quimioterápicos na linhagem de melanoma murino para isolamento de vesículas extracelulares.

3 - Caracterização e incorporação de vesículas extracelulares liberadas por células de melanoma murino tratadas com quimioterápicos.

4 - Avaliação da morte celular induzida por quimioterápicos e o efeito da presença de vesículas extracelulares liberadas por células de melanoma murino.

5 - Avaliação do crescimento tumoral in vivo na presença de vesículas extracelulares liberadas por células de melanoma previamente tratadas com quimioterápicos. 


\section{MÉTODOS}

\subsection{Manutenção das células em cultura}

A linhagem de células de melanoma murino B16-F10 foi cultivada em estufa à $37 \stackrel{\circ}{\circ} \mathrm{C}$, em atmosfera de $5 \% \mathrm{CO}_{2}$ umidificada, em meio Roswell Park Memorial Institute (RPMI1640), pH 7,2, contendo 10\% de soro fetal de bovino (SFB). Para manutenção em cultura, as células foram lavadas com uma solução de fosfato-salino tamponado (PBS) com $1 \mathrm{mM}$ de ácido etilenodiamino tetra-acético (EDTA) e soltas das garrafas utilizando tripsina. Para inativar a ação da trispina, foi adicionado meio de cultura com $10 \%$ de SFB. As células foram centrifugadas a $300 \mathrm{~g}$ por 2 minutos e uma alíquota foi separada para contagem de células pelo método de azul de tripan em câmara de Neubauer. $O$ sobrenadante foi retirado e as células foram homogeneizadas em meio de cultura suplementado com $10 \%$ de SFB (R10) e transferidas para outro frasco de cultura ou conservadas em SFB contendo 10\% de dimetilsulfóxido (DMSO) a $-80^{\circ} \mathrm{C}$ até sua utilização.

\subsection{Avaliação da viabilidade e proliferação celular}

A proliferação celular foi analisada após 24,48 e 72 horas. As células foram coradas com o corante azul de tripan (v:v) e a quantidade estimada em câmara de Neubauer. $O$ corante é externalizado por células viáveis, células marcadas com o corante foram consideradas inviáveis e o percentual de viabilidade celular foi estabelecido.

\subsection{Depleção das vesículas extracelulares do soro fetal bovino}

O SFB foi centrifugado à $100000 \mathrm{~g}$ durante 16 horas para retirada de VEs. Após esse período o soro foi filtrado a vácuo no filtro de 0,2 micras e armazenado a $4^{\circ} \mathrm{C}$. 


\subsection{Avaliação da toxicidade das drogas}

\subsubsection{Viabilidade celular}

A atividade metabólica da célula foi analisada através da formação de cristais de formazan por mitocôndrias, avaliando assim, a viabilidade celular. Ao final dos tempos de tratamento, foi adicionado $10 \mu \mathrm{L}$ de solução de sal de tetrazolium (MTT) na concentração final de $5 \mu \mathrm{g} / \mathrm{mL}$ em cada poço. As placas foram incubadas por 4 horas em estufa à $37^{\circ} \mathrm{C}$. Após esta incubação, foi adicionado $80 \mu \mathrm{L}$ de tampão de solubilização em cada poço e as placas foram mantidas durante 16 horas em estufa a $37^{\circ} \mathrm{C}$. Após observar a completa solubilização dos cristais, foi realizada a leitura da densidade óptica em espectrofotômetro, no canal de $595 \mathrm{~nm}$.

\subsubsection{Ensaio de clonogenicidade}

Para avaliar a capacidade das células em formar colônias após o tratamento com as drogas, as células (previamente tratadas) foram plaqueadas em baixa densidade (300 células em placas individuais de $3,5 \mathrm{~cm}$ ) e mantidas em condições de cultura, mencionadas anteriormente, por no máximo 15 dias. Após observar clones visíveis macroscopicamente, as células foram fixadas com solução de PBS contendo 1\% de formol e coradas com solução de PBS contendo $0,1 \%$ de cristal violeta, quantificando assim os clones de cada condição. O percentual de células formadoras de clones foi obtido calculandose o número de clones formado multiplicado por 100 , dividido pelo número inicial de células plaqueadas.

\subsubsection{Avaliação do ciclo celular}

As fases do ciclo celular foram avaliadas pelo método de incorporação de iodeto de propídeo (PI) através de citometria de fluxo. As amostras foram fixadas em solução de etanol (70\%) e armazenadas em freezer a $-20 \stackrel{\circ}{\circ}$. Para a citometia, as células foram centrifugadas a $700 \mathrm{~g}$ para retirar o etanol e foram ressuspendidas em PBS. As células foram novamente centrifugadas e o pellet resultante foi incubado em solução contendo PI $\left(\mathrm{C}_{\mathrm{f}}\right.$ : $\left.20 \mu \mathrm{g} / \mathrm{mL}\right)$, triton X100 $(0,1$ $\%$ v:v), RNAse ( $C_{\mathrm{f}}: 200 \mu \mathrm{g} / \mathrm{mL}$ ) em PBS. Após o tempo de incubação foi realizada a leitura no citometro de fluxo BD FACSCALIBUR e a análise foi realizada pelo software Cell Quest. A fluorescência do PI foi captada nos 
canais FL2 (laser fluorescente 2 - amarelo) e FL3 (laser fluorescente 3 vermelho), avaliando assim as fases do ciclo e morte celular.

\subsection{Isolamento de vesículas extracelulares}

Células da linhagem B16-F10 foram cultivadas em frascos de $75 \mathrm{~cm}^{2}$ utilizando meio RPMI suplementado de SFB depletado de vesículas. Ao atingirem a confluência adequada (aproximadamente 50 \% para CDDP e $30 \%$ para TMZ), foram tratadas com o quimioterápico na concentração e tempo previamente determinados $(360 \mu \mathrm{M}$ de TMZ durante 72 horas e $25 \mu \mathrm{M}$ de CDDP durante 24 horas). Após o tratamento dessas células, foi coletado o sobrenadante de cada condição experimental, para obtenção das VEs. O sobrenadante foi processado de acordo com o protocolo modificado de Théryet al (2006). O esquema abaixo mostra as etapas de centrifugações para isolar as VEs.

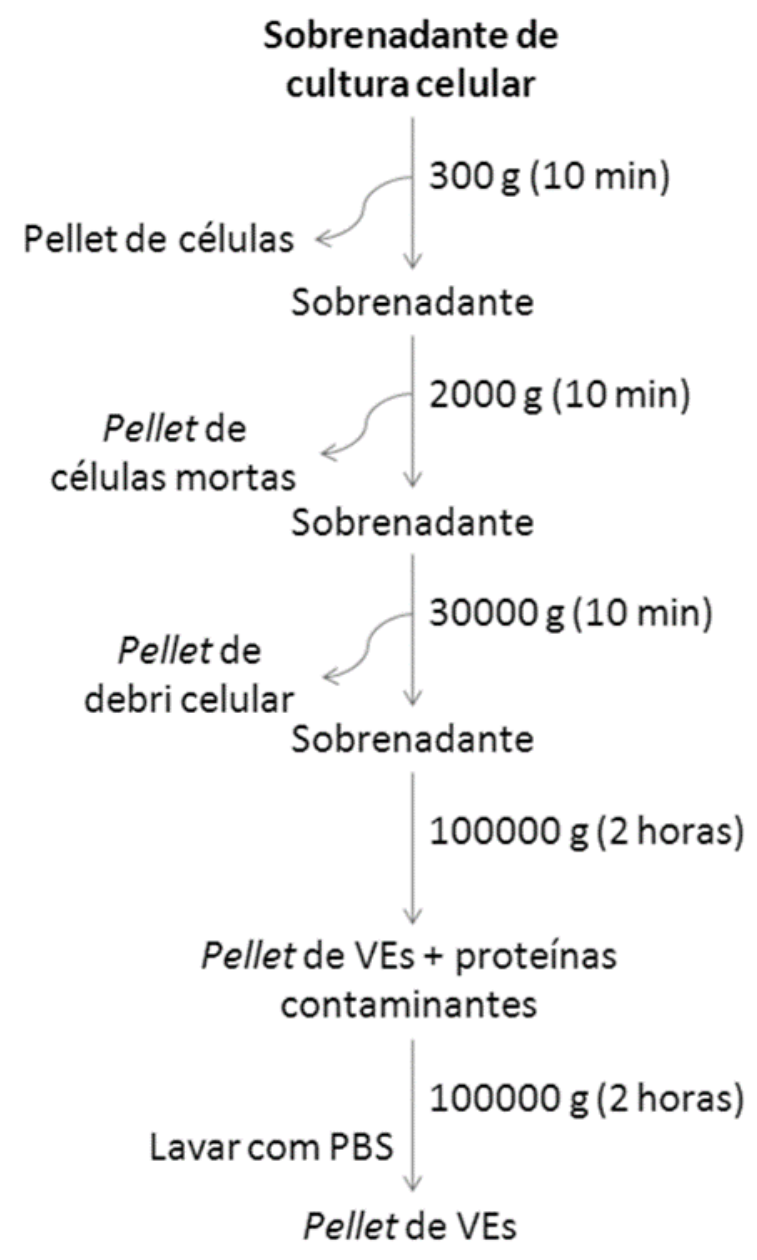

Figura 5: Processo de centrifugações para isolar as VEs. Figura modificada de Théry et al (2006) [Théry C et al, 2006] 
Para a obtenção das VEs, o meio condicionado de cultura celular foi coletado e centrifugado durante 10 minutos a $300 \mathrm{~g}$ em centrífuga convencional, enquanto as células aderidas na garrafa de cultura foram quantificadas em câmara de neubauer. Para eliminar possíveis células e corpúsculos apoptóticos presentes no sobrenadante, o mesmo foi centrifugado durante 10 minutos a $2000 \mathrm{~g}$ em ultracentrifuga. O sobrenadante resultante foi transferido para outro tubo e novamente centrifugado durante 30 minutos a $30000 \mathrm{G}$ em ultracentrifuga, após isso, o sobrenadante foi centrifugado a $100000 \mathrm{G}$ durante 2 horas na temperatura de $4^{\circ} \mathrm{C}$. O precipitado foi ressuspendido em PBS filtrado e centrifugado novamente na mesma temperatura e rotação. Ao final dessa etapa o precipitado foi ressuspendido em RPMI na proporção de $1 \mathrm{~mL}$ a cada $1 \times 10^{7}$ células e armazenado a $-80^{\circ} \mathrm{C}$ até a sua utilização.

\subsection{Quantificação das vesículas extracelulares}

As VEs uma vez isoladas foram ressuspensas em $200 \mu \mathrm{L}$ de tampão de lise proteica NP40 Lysis Buffer contendo $2 \mu \mathrm{g} / \mathrm{mL}$ de aprotinina e $1 \mu \mathrm{M}$ de PMSF. O lisado de VEs foi quantificado através da curva de concentração de albumina (BSA do inglês bovine serum albumine) e foi feita a leitura da densidade óptica em espectrofotômetro, no comprimento de onda de $595 \mathrm{~nm}$.

Para avaliar o perfil de tamanho das proteínas carregadas por VEs, realizamos uma eletroforese de proteínas. O lisado proteico obtido para quantificar a massa proteica das VEs foram separadas em gel de separação 12 $\%$ contendo acrilamida, tampão lower (contendo Tris e SDS em $\mathrm{dH}_{2} \mathrm{O}$ e o pH $8,8)$, APS $10 \%$ e temed em água destilada $\left(\mathrm{dH}_{2} \mathrm{O}\right)$, e o gel de empilhamento contendo acrilamida, tampão upper (contendo Tris e SDS e dH2O e o pH 6,8), APS $10 \%$ e temed em $\mathrm{dH}_{2} \mathrm{O}$. Foi utilizado o tampão de corrida contendo Tris, glicina e $\mathrm{SDS}$ em $\mathrm{dH}_{2} \mathrm{O}$ e o $\mathrm{pH}$ 8,3. A eletroforese foi realizada na voltagem 100 $v$ durante 90 minutos. Após o tempo de corrida, o gel foi corado com azul de coomasie.

Quantificamos as VEs utilizando o equipamento de rastreamento de nanopartículas, NanoSight, da Malvern Instruments (Malvern, UK). 


\subsection{Avaliação da Incorporação das vesículas extracelulares}

Para avaliar se as células são capazes de incorporar as VEs, foi necessário marcar as mesmas com uma substância fluorescente. Para essa análise, foram testadas duas metodologias de marcação. A primeira, as células da linhagem B16-F10 foram cultivadas em frascos de cultura de $75 \mathrm{~cm}^{2}$ de área. Ao atingirem aproximadamente $60 \%$ de confluência foram tratadas com os quimioterápicos juntamente com o marcador fluorescente de membrana celular, VybrantDiO (DiO) da Invitrogen na proporção 1:200 em meio de cultura. As células foram incubadas com $4 \mathrm{~mL}$ da solução durante 15 minutos a $37^{\circ} \mathrm{C}$. Após esse período, foram adicionados $11 \mathrm{~mL}$ de meio RPMI com $10 \%$ SFB e mantidas overnight. As VEs marcadas foram isoladas pelo método descrito anteriormente. A segunda metodologia de marcação, as VEs já isoladas foram marcadas com DiO na proporção 1:200 em solução contendo VEs em suspensão e incubadas durante 2 horas. Após esse período, as VEs foram centrifugadas a $100000 \mathrm{~g}$ durante 2 horas. O pellet resultante foi ressuspendido e armazenado a $-80 \stackrel{\circ}{ } \mathrm{C}$ até a utilização.

Para a análise de incorporação, as células da linhagem B16-F10 foram plaqueadas em lamínulas circulares com $13 \mathrm{~mm}$ de diâmetro depositadas em poços de placas de 24 poços. Foram plaqueadas $2 \times 10^{4}$ células em meio RPMI suplementado de SFB depletados de VE (SFBd) e mantidas overnight. As VEs, previamente marcadas, foram incubadas em paralelo aos controles nas densidades de 10, 50 e $100 \mu \mathrm{g} / \mathrm{mL}$ e mantidas durante 24 horas em condição de cultura. Ao término da incubação, as células foram fixadas utilizando-se uma solução de paraformaldeído $1 \%$. O núcleo das células foi marcado pelo traçador fluorescente HOESCHT $33258\left(\mathrm{C}_{\mathrm{f}}: 25 \mu \mathrm{g} / \mathrm{mL}\right.$ ) e os filamentos de actina do citoesqueleto foram marcados por faloidina conjugada a rodamina. As lâminas foram montadas utilizando-se uma solução de glicerol:PBS (1:1) e mantidas a $4^{\circ} \mathrm{C}$ até a análise. As análises foram realizadas no microscópio de fluorescência Eclipse E600 (Nikon, Japão), utilizando-se o software ACT-1 (Nikon, Japão) para captura da imagem. A quantificação do número de células e o número de células que incorporam VEs foi realizada no software Image-J utilizando o plugin Cell Counter. 


\subsection{Avaliação de crescimento tumoral in vivo}

As células de melanoma B16-F10 $\left(2 \times 10^{4}\right)$ foram inoculadas, em conjunto com $1 \times 10^{9}$ VEs oriundas de células tratadas com quimioterápicos, no subcutâneo de camundongos C57BL/6, e o crescimento do tumor foi acompanhado diariamente. O volume do tumor foi mensurado com um paquímetro obtendo-se o diâmetro maior e o menor do volume tumoral. Foi aplicado o cálculo para estimar a área da elipse para estimar o volume tumoral. [Onuchic et al, 2012]

\section{0,5236 x Diâmetro Maior x Diâmetro Menor}

O crescimento do tumor foi acompanhado diariamente até o maior tumor atingir $1 \mathrm{~cm}^{3}$. A finalização do experimento foi realizada utilizando-se anestesia intraperitoneal com quetamina (100 mg/kg) e xilazina (10 mg/kg) e a eutanásia ocorreu em câmara de $\mathrm{CO}_{2}$. Os tumores foram removidos cirurgicamente e a massa dos tumores foram pesadas em uma balança.

\subsection{Análise estatística}

As análises estatísticas foram realizadas comparações entre os grupos utilizando o teste ANOVA de uma via ou ANOVA de duas vias, seguido da correção de Bonferroni, considerando valor de significância para $p<0,05$. $A$ análise estatística foi realizada com o auxílio do software GraphPad Prism versão 4.0 (San Diego California USA). 


\section{RESULTADOS}

\subsection{Padronização das condições de cultura celular para geração de vesículas extracelulares}

Observando as células B16-F10 incubadas com o produto resultante da ultracentrifugação do meio de cultura suplementado com $10 \%$ de SFB, juntamente com o traçador fluorescente DiO (figura 6), podemos sugerir que 0 meio de cultura suplementado com $10 \%$ de SFB pode conter VEs provenientes do soro, uma vez que no controle somente com meio de cultura RPMI, essas estruturas não foram observadas. Isso sugere que as VEs oriundas do SFB podem interferir nos experimentos que visam utilizar VEs liberadas por células de melanoma. A alternativa utilizada foi depletar as VEs do SFB centrifugando a 100000 g durante 16 horas, gerando assim o SFB depletado de vesículas (SFBd).

A VEs do meio de cultura
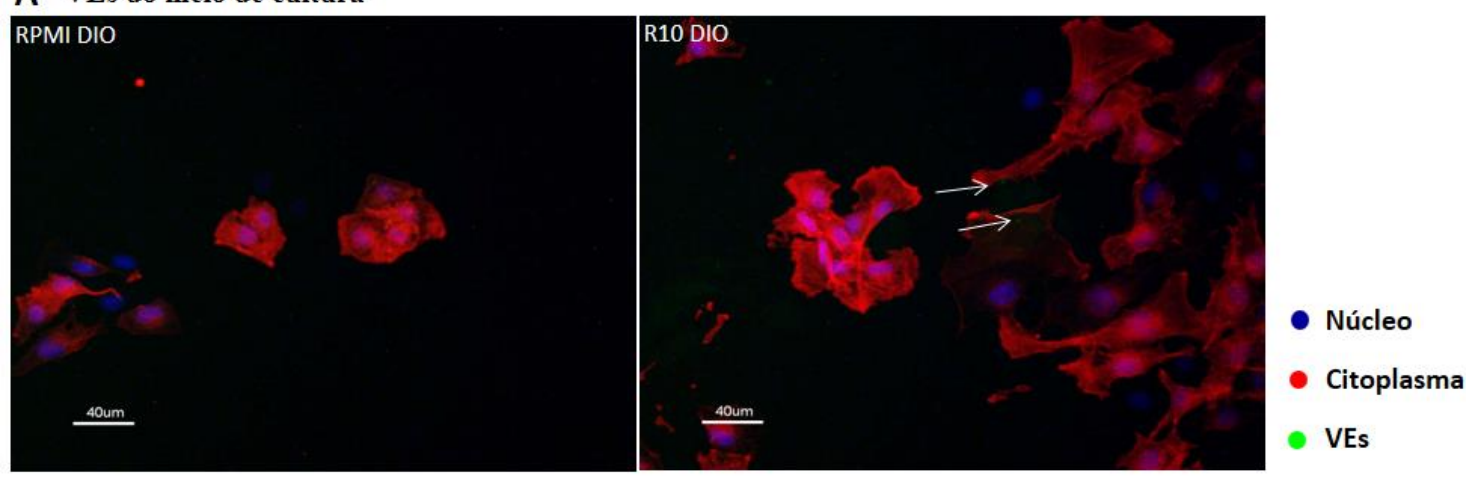

Figura 6: Presença de VEs no SFB. A) Observação por microscopia de fluorescência de VE contaminante no meio de cultura sendo: "RPMI DIO" o meio de cultura RPMI incubado com DiO e "R10 DIO" o meio de cultura suplementado com $10 \%$ de SFB incubado com DiO. As setas indicam VEs oriundas do SFB marcadas com DiO

Para determinar as condições de cultivadas células B16-F10 com a finalidade de isolar as VEs liberadas pelas mesmas, e, garantir a origem das VEs, sem a interferência de VEs do SFB, foi realizado um experimento de cultivo de células em diferentes concentrações de SFB. Em conjunto com esse experimento, foi realiza uma curva de toxicidade da CDDP. 

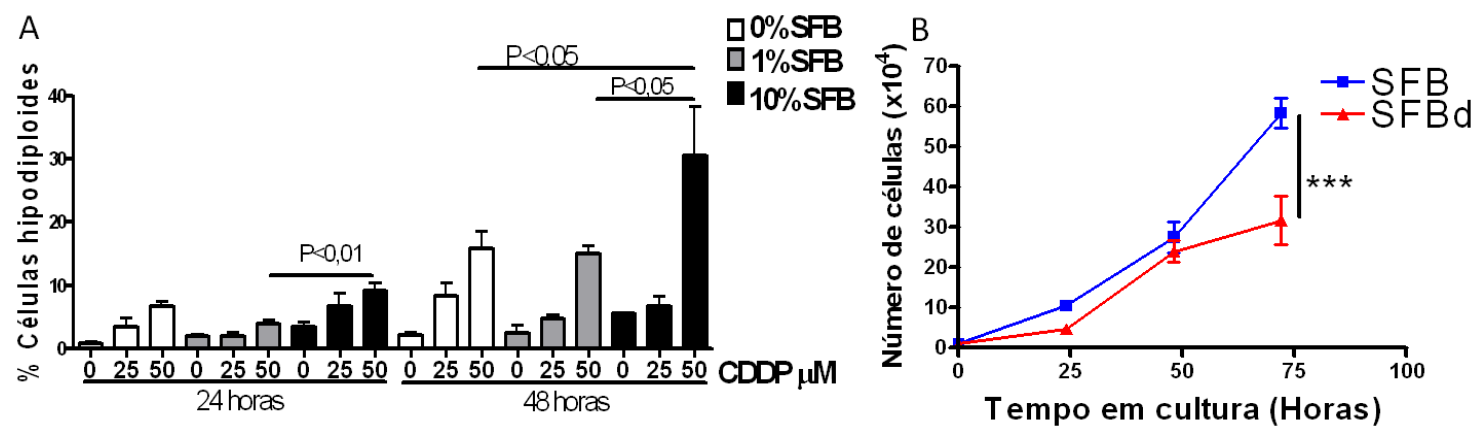

Figura 7: Padronização da obtenção de VEs. A) Curva de toxicidade à CDDP em diferentes condições de privação de nutrientes. B) Curva de crescimento das células B16-F10, comparando o crescimento entre SFB e SFB depletado de VEs (SFBd).

A curva de toxicidade à CDDP em diferentes condições de privação de nutrientes apresentada na figura 7.A mostra que houve um menor percentual de células hipodiploides em resposta ao tratamento com CDDP $(50 \mu \mathrm{M})$ na condição de $1 \%$ de SFB quando comparado ao mesmo tratamento com $10 \%$ de SFB. E a exposição à $50 \mu \mathrm{M}$ da droga durante 48 horas de tratamento mostra que o acúmulo de células hipodiploides na condição "R10" é significativamente maior que nas condições de privação de soro ou com $1 \%$ de SFB. Como esperado, a privação de nutrientes diminui a resposta das células ao quimioterápico CDDP.

Para avaliar se o SFBd interfere no cultivo das células B16-F10, foi realizada uma curva de crescimento comparando-se o crescimento destas células cultivadas com SFB ou SFBd durante 72 horas. O resultado apresentado na figura 6.B mostra que o número de células cultivadas com SFBd é menor quando comparado ao número de células cultivadas somente com SFB. Com base nos resultados da figura 7.B, otimizamos a metodologia de plaqueamento, aumentando o número inicial de células.

\subsubsection{Determinação da concentração das drogas CDDP e TMZ}

Para avaliar se o SFBd interfere na resposta celular ao tratamento com quimioterápicos, foi realizada uma curva de toxicidade para estas drogas. $O$ objetivo desta análise é determinar a concentração das drogas a serem utilizadas nos demais experimentos, em que observamos a resposta celular a droga, mas não a morte celular. 


\subsubsection{Toxicidade da CDDP}

Para avaliar a citotoxicidade do quimioterápico cisplatina (CDDP) na linhagem B16-F10, estas células foram tratadas com diferentes concentrações de CDDP por 24 e 48 horas.

A avaliação de morte e fases do ciclo celular mostra que células tratadas com $50 \mu \mathrm{M}$ de CDDP durante 24 horas aumenta significativamente o percentual de células hipodiploides (figura 8.A), e as fases do ciclo celular mostram que tanto 25 quanto $50 \mu \mathrm{M}$ de CDDP aumentam o percentual da população celular na fase SG2M sugerindo que a droga é eficiente em ambas as concentrações. Já em 48 horas de tratamento, a concentração de $50 \mu \mathrm{M}$ de CDDP aumenta drasticamente a população de células hipodiploides, além disso, as concentrações de 25 e $50 \mu \mathrm{M}$ aumentam o percentual da população celular na fase SG2M.
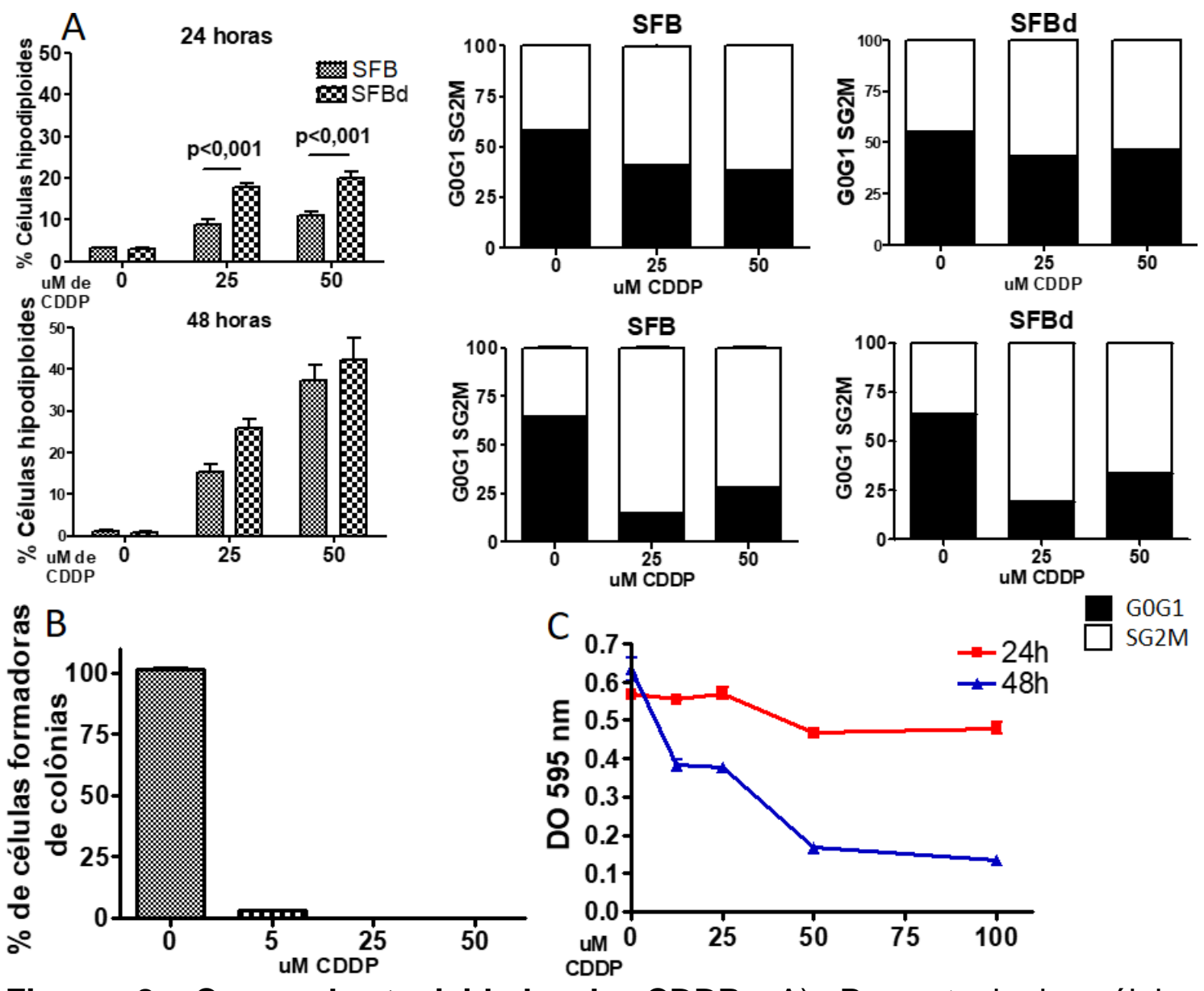

Figura 8: Curva de toxicidade da CDDP. A) Percentual de células hipodiploides (esquerda) e percentual de células nas fases do ciclo celular (direita) após 24 e 48 horas de tratamento analisado por incorporação de iodeto de propídeo. B) Análise de formação de clones por ensaio clonogênico. C) Análise de viabilidade celular por MTT. 
$\mathrm{Na}$ avaliação de sobrevivência e proliferação celular observada pelo ensaio de formação de colônias, apresentado na figura 8.B, as concentrações de 25 e $50 \mu \mathrm{M}$ de CDDP por 24 horas também leva à diminuição da capacidade das células em formar clones. $O$ resultado da curva de toxicidade da CDDP avaliada por MTT, apresentado na figura 8.C, mostra que o tratamento com $50 \mu \mathrm{M}$ de CDDP por 24 horas diminui a atividade da enzima succinatodesidrogenase, sugerindo a diminuição da viabilidade celular. E as concentrações de 25 e $50 \mu \mathrm{M}$ de CDDP em 48 horas de tratamento reduz ainda mais a viabilidade das células. Esses resultados mostram que as concentrações de 25 e $50 \mu \mathrm{M}$ de CDDP são citotóxicas para as células B16F10. Contudo, a concentração de $25 \mu \mathrm{M}$ por 24 horas leva a um aumento discreto da quantidade de células hipodiploides, o que mostra ser uma condição adequada para avaliar as vesículas liberadas nessa situação.

\subsubsection{Toxicidade da TMZ}

As células de melanoma B16-F10 foram tratadas com diferentes concentrações de temozolamida por 24, 48 e 72 horas.

$\mathrm{Na}$ avaliação de morte e fases do ciclo celular apresentada na figura 9.A, observamos que o tratamento com TMZ em diferentes concentrações por 24 horas apresenta diferença significativa no percentual de células hipodiploides nas concentrações de $27 \mu \mathrm{M}$ e $81 \mu \mathrm{M}$ quando comparado ao controle negativo, já as fases do ciclo celular apresentam aumento no percentual de células na fase SG2M nas concentrações de $81 \mu \mathrm{M}$ e $360 \mu \mathrm{M}$ quando comparadas ao controle negativo.

Em 48 horas de tratamento não há diferença significativa no percentual de células hipodiploides, mas existe diferença significativa no percentual de células da população na fase SG2M, quando tratadas com $360 \mu \mathrm{M}$ de TMZ. Em 72 horas de tratamento com $360 \mu \mathrm{M}$ de TMZ, há um aumento significativo no percentual de células hipodiploides quando comparado com o controle negativo e as demais concentrações. Esse aumento também é observado no percentual da população em SG2M. Esses resultados sugerem que a droga é eficiente na concentração de $360 \mu \mathrm{M}$ durante 72 horas de tratamento. 

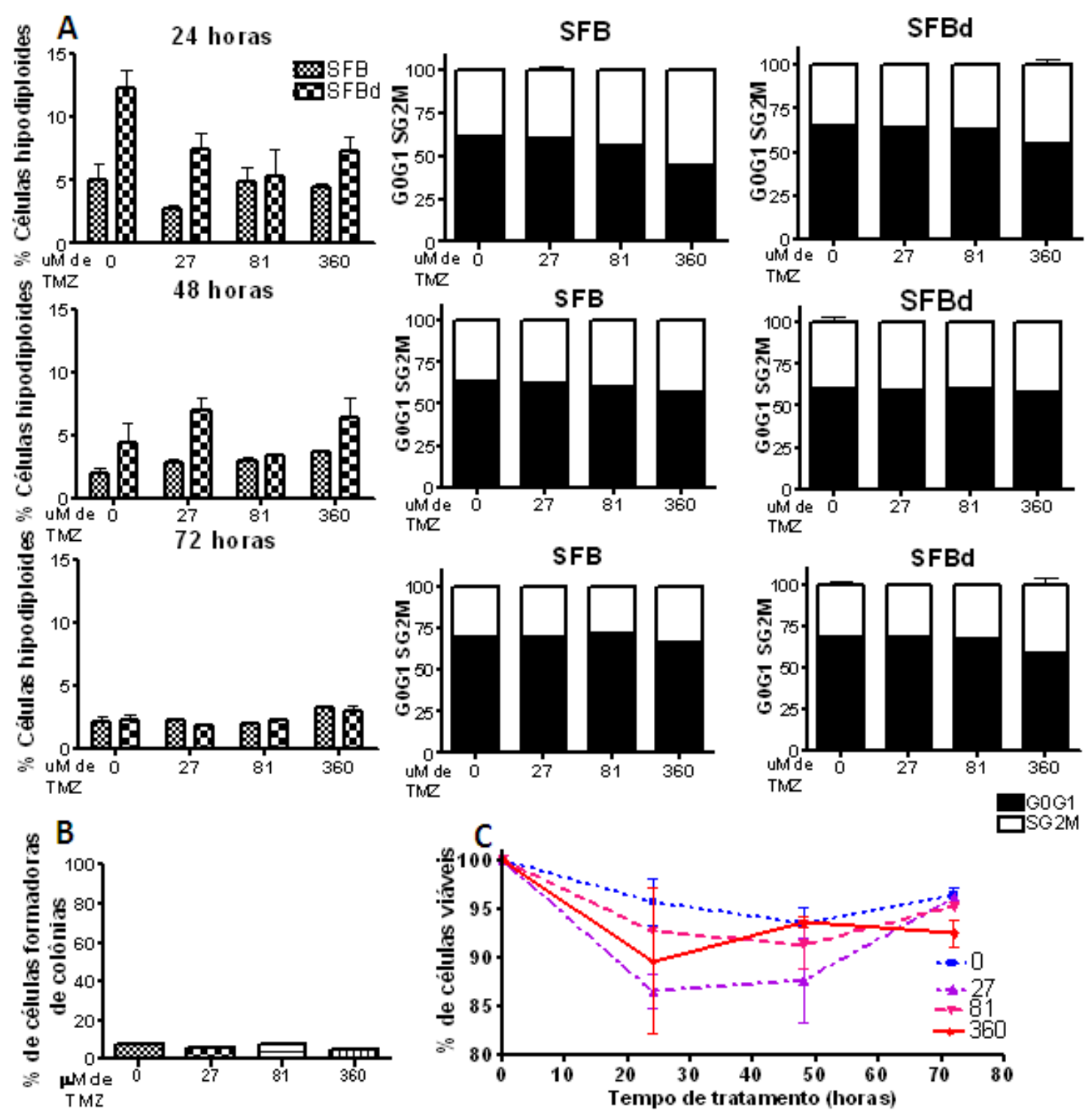

Figura 9: Curva de citotoxicidade da TMZ. A) Morte e fases do ciclo celular em 24, 48 e 72 horas de tratamento com temozolomida e analisado por incorporação de iodeto de propídeo. B) Análise de formação de clones por ensaio clonogênico. C) Análise de viabilidade por Azul de tripan.

Na figura 9.B, onde avaliamos a sobrevivência celular por meio do ensaio de formação de colônias, observamos que não há diferença significativa na capacidade das células em formar clones. O resultado da viabilidade celular quantificada pelo método de coloração Azul de tripan, apresentado na figura 9.C, mostra que em 72 horas de tratamento com $360 \mu \mathrm{M}$ de $\mathrm{TMZ}$, diminui a viabilidade celular em $8 \%$, e as demais concentrações apresentaram diminuição da viabilidade em $5 \%$.

Os resultados mostram que apesar de haver diferença no crescimento das células, entre células cultivadas em SFB ou SFBd, não há diferença no percentual de células hipodiploides entre os tipos de SFB em ambos os 
tratamentos, CDDP ou TMZ. Esses resultados reforçam a ideia de que a estratégia mais adequada para garantir a origem das VEs é usar o SFB livre de vesículas (SFBd).

\subsubsection{Otimização de tratamento com TMZ}

Para determinar a melhor estratégia para a geração de VEs oriundas de células tratadas com $T M Z$, foi realizada uma curva de toxicidade avaliando a concentração da droga e o tempo de tratamento.

A curva de toxicidade apresentada na figura 11.A mostra que há aumento no percentual de células hipodiploides somente na concentração de $360 \mu \mathrm{M}$ de TMZ após 72 horas de tratamento, mas há aumento na população de células na fase SG2M no controle após esse período. Esse resultado sugere que a manutenção das células em cultura durante 72 horas sem a adição de meio de cultura (Esquema 1) pode alterar o ciclo celular, indicando que há aumento de células em SG2M, provavelmente pela diminuição de nutrientes no meio de cultura após esse período. Para verificar essa condição, realizamos o mesmo esquema de tratamento descrito acima, no entanto, após 48 horas de tratamento com TMZ foi adicionado um reforço desta droga. Ao mesmo tempo, nas condições de controle, após 48 horas foi adicionado meio de cultura suplementado com $10 \%$ de SFB (Esquema 2).

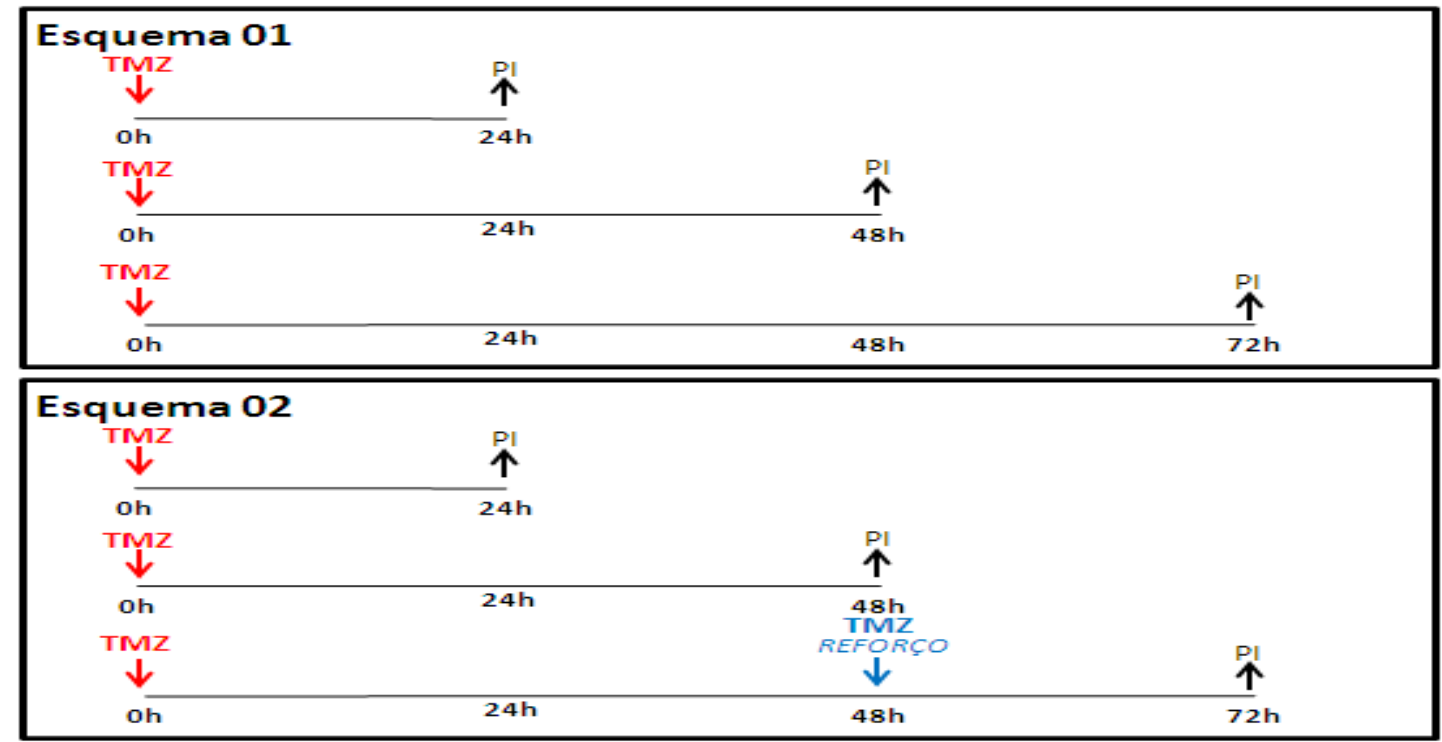

Figura 10: Protocolos de tratamentos com TMZ. Esquema 1) Tratamento com $360 \mu \mathrm{M}$ de TMZ em 24, 48 e 72 horas. Esquema 2) Tratamento com 360 $\mu \mathrm{M}$ de TMZ em 24, 48 e 72 horas com reforço do tratamento em 48 horas. 
O resultado apresentado na figura 11.B mostra que, com a adição de meio de cultura após 48 horas não observamos aumento do percentual de células na fase SG2M no controle após 72 horas. Além disso, houve um aumento na porcentagem de células hipodiploides após 72 horas de tratamento somente na concentração de $360 \mu \mathrm{M}$ de TMZ.
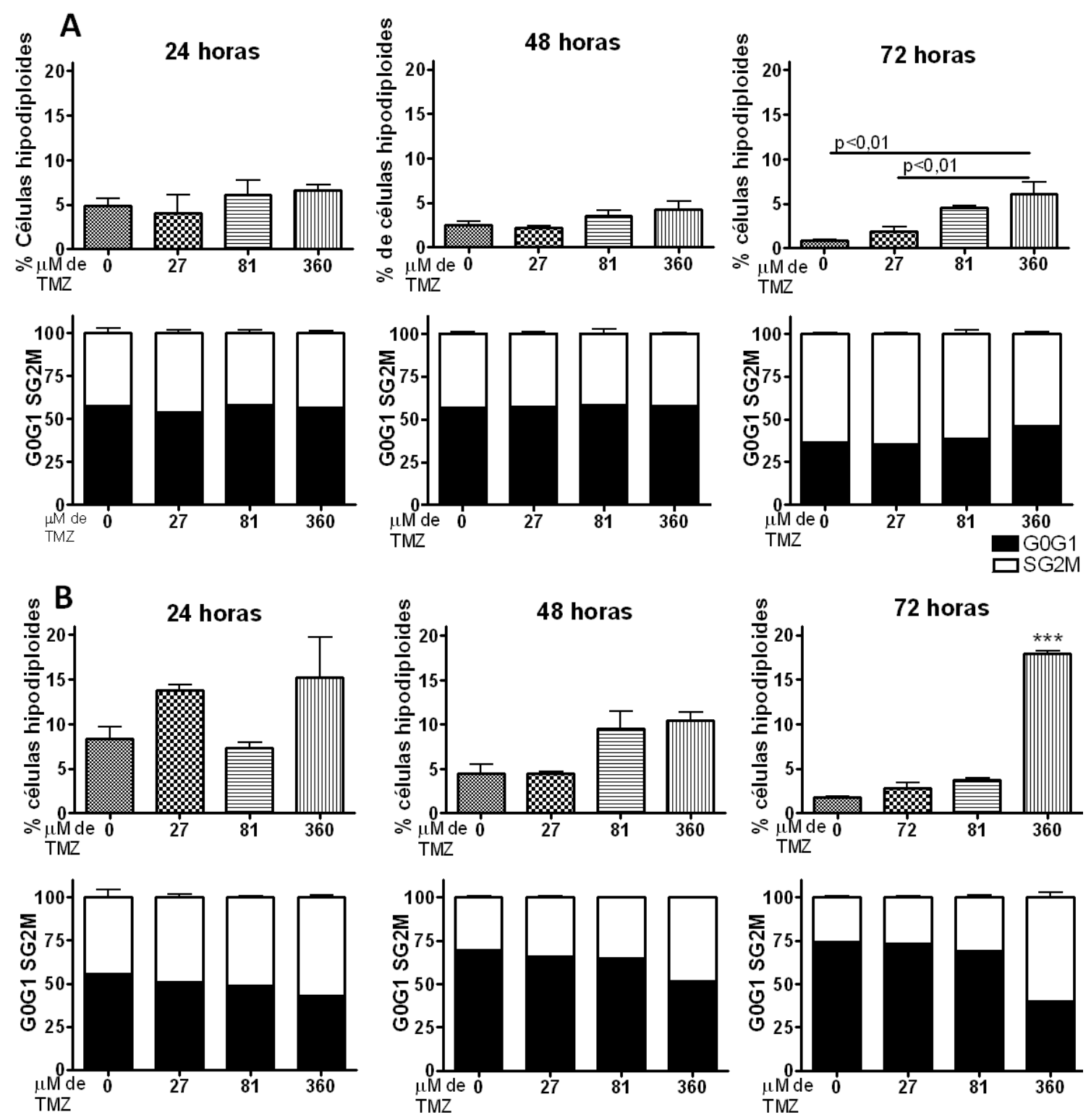

Figura 11: Otimização do tratamento com TMZ. A) Morte e fases do ciclo celular em resposta ao tratamento com TMZ sem reforço. B) com reforço. $\left({ }^{* \star *}\right)$ $p<0,001$ comparado às demais concentrações.

O dano gerado pela TMZ é reparado pela enzima MGMT que remove o grupo metil na posição $\mathrm{O} 6$ da guanina, e uma vez alquilada, esta perde sua atividade [9]. Com isso delineamos um experimento onde o reforço de TMZ seria realizado após 24 horas de tratamento com esta droga. A hipótese é que após 24 horas de tratamento com TMZ haveria uma diminuição de MGMT, 
tornando essa célula mais suscetível a um segundo tratamento com TMZ (reforço).

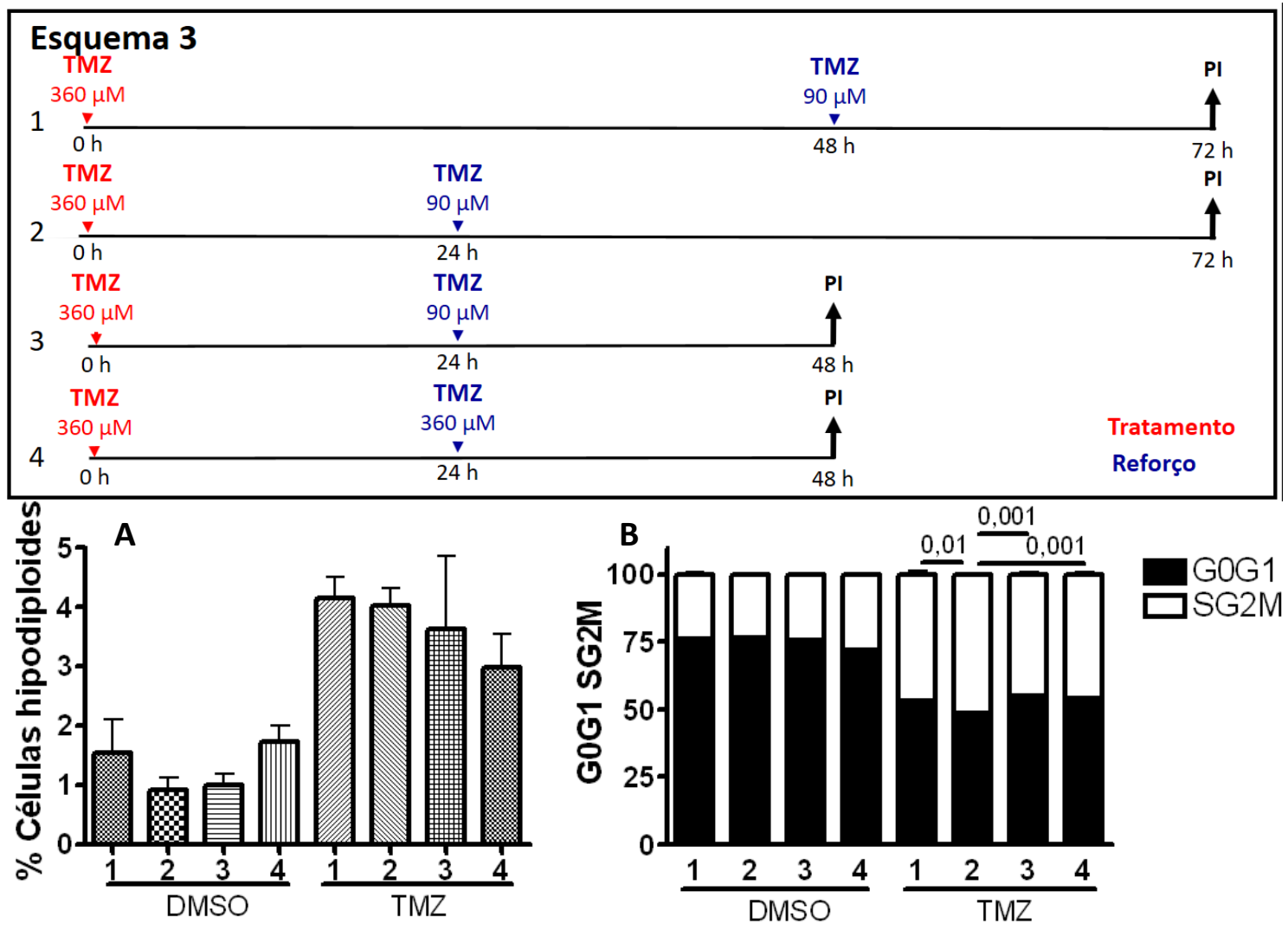

Figura 12: Otimização do tratamento com reforço da TMZ. Esquema 3) Tratamento com TMZ em diferentes tempos de reforço da droga. A) Morte celular avaliada por incorporação de PI. B) Fases do ciclo celular (direita).

A figura 12 mostra que não existe diferença no percentual de células hipodiploides entre os tratamentos com diferentes tempos de reforço. No entanto, reforçar o tratamento após 24 horas (2) resulta no aumento da população celular na fase SG2M quando comparado ao reforço após 48 horas (1). Como não houve uma grande diferença de resposta a TMZ, continuamos os experimentos com o esquema 1.

\subsubsection{Padronização da quantificação de VEs}

Para determinar a concentração de VEs utilizada para avaliar o efeito das mesmas sobre as células tumorais, quantificamos inicialmente a massa proteica das VEs. A metodologia foi otimizada comparando-se a massa proteica dessas VEs com a quantificação de VEs utilizando o equipamento nanosight. 
A quantificação do número de VEs mostra que existe diferença significativa na concentração de VEs oriundas de células tratadas com CDDP e seu controle (figura 13.A superior), assim como observamos diferença significativa entre VEs oriundas de células tratadas com TMZ e seu controle (figura 13.A inferior). A quantificação proteica mostra que existe diferença significativa entre VEs oriundas de células tratadas com CDDP (VE CDDP) e seu controle (VE PBS) (figura 13.B superior). No entanto, esta diferença não é observada no caso de VEs oriundas de células tratadas com TMZ (VE TMZ) e seu controle (VE DMSO) (figura 13.B inferior).
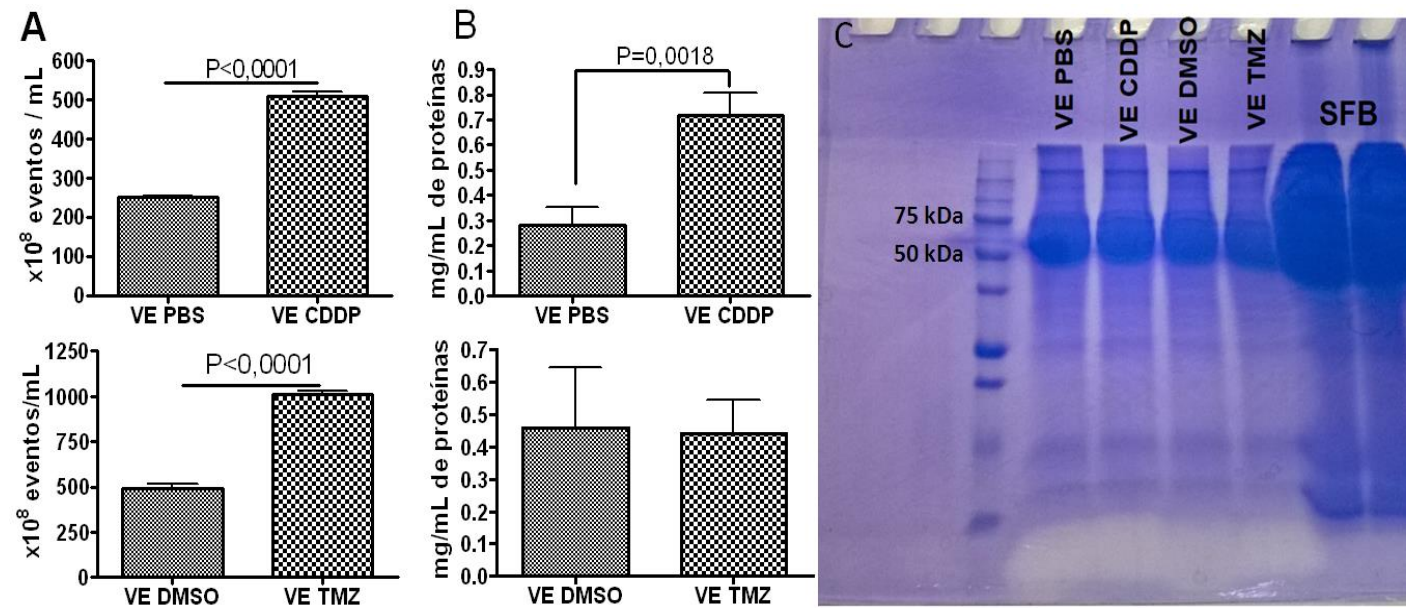

Figura 13: Padronização da quantificação de VEs. A) Quantificação do número de VEs. B) Quantificação de proteínas presentes em VEs oriundas de células de melanoma. C) Eletroforese de proteínas. Amostra de proteínas isoladas a partir de VEs oriundas de células tratadas com CDDP (VE-CDDP) e TMZ (VE-TMZ) e seus controles PBS e DMSO (VE-PBS) e (VE-DMSO), respectivamente, e amostras com $10 \%$ de SFB.

Como existe diferença entre os métodos de quantificação de VEs, realizamos uma eletroforese de proteínas para observar se as VEs oriundas de células tratadas com CDDP (VE-CDDP) ou TMZ (VE-TMZ) estariam carregando mais proteínas do que as VEs controles (VE-PBS ou VE-DMSO).

O resultado apresentado na figura 13.C mostra que existe uma grande quantidade da proteína albumina nas amostras, podendo mascarar a quantificação proteica das VEs. Isso indica que o método de isolamento das VEs é eficiente para isolá-las, mas não é capaz de separar as proteínas presentes no SFB. Dessa forma, seguimos os experimentos de acordo com a quantificação de VEs, avaliadas no equipamento Nanosight. 


\subsubsection{Padronização da marcação de VEs}

Para avaliar se as VEs geradas por células tumorais são incorporadas por células tumorais, foi necessário utilizar um marcador fluorescente (DiO) que marca a membrana fosfolipídica das células. Para padronização, comparamos a eficiência de marcação de VEs antes (pré) e após (pós) o isolamento das mesmas.
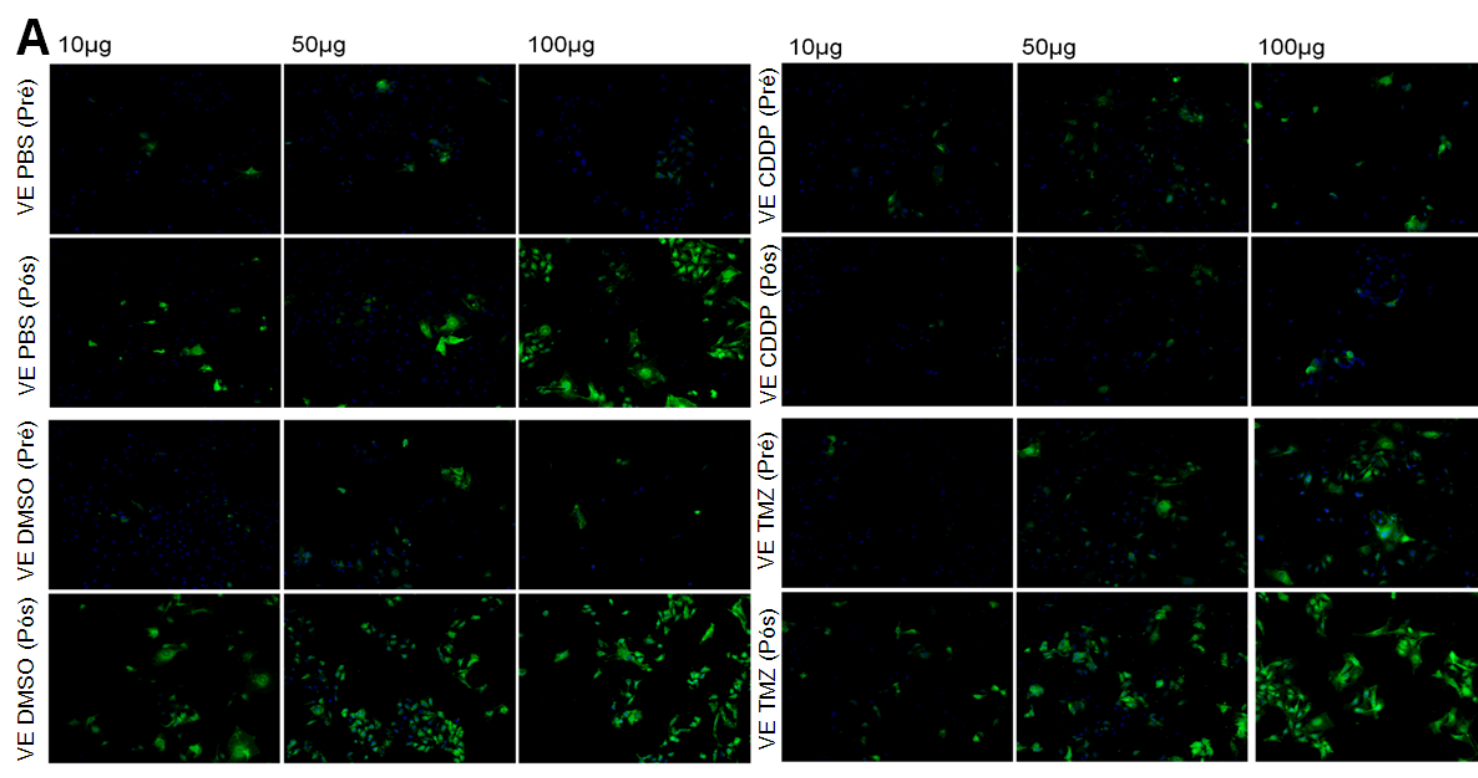

B

- VEs incorporadas
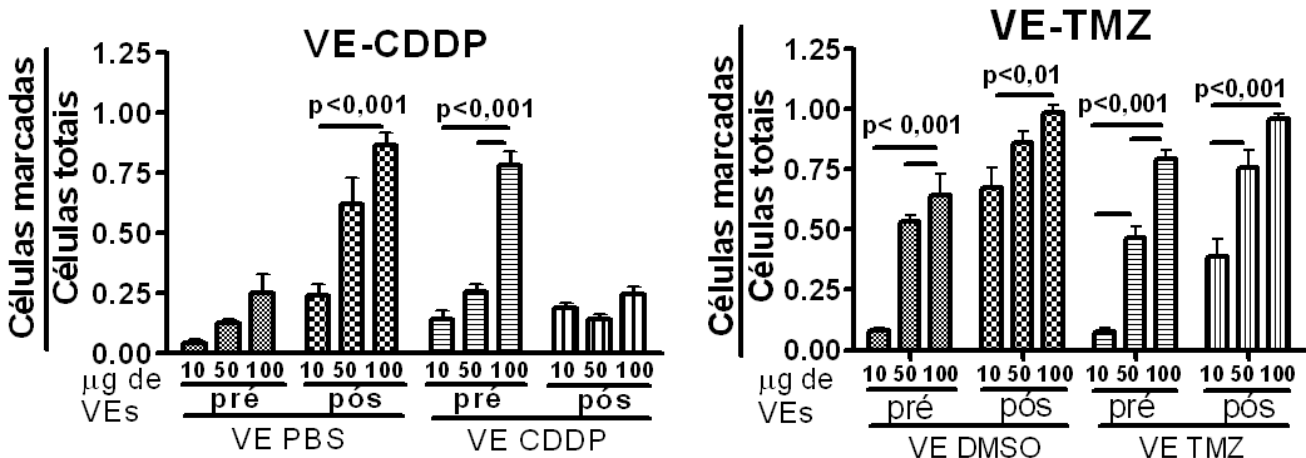

Figura 14: Padronização da marcação de VEs. A) Imagens obtidas por microscópio de fluorescência de VEs marcadas com DiO (verde) incorporadas por células de melanoma. B) Razão de células que incorporaram VEs em relação ao número total de células (quantificação nuclear).

O resultado apresentado na figura 14.A mostra que a incorporação de VEs marcadas após o isolamento é mais eficiente do que a incorporação de VEs marcadas antes do isolamento. Ou seja, com a mesma quantidade de VEs 10, 50 ou $100 \mu \mathrm{g}$, observamos que há mais células marcadas na condição "pós" quando comparada à condição "pré", em todos os tratamentos. A incorporação de VEs oriundas de células tratadas com CDDP foi menor quando 
comparada às VEs oriundas de células tratadas com PBS, pois observamos um menor número de células marcadas com VE CDDP em relação a VE PBS (Figura 14.A). Esse resultado é mais evidente nas VEs "pós" quando comparado as VEs "pré". A quantificação de 5 imagens resultou no maior número de células marcadas por VE-CDDP "pré" em relação a VE-PBS "pré", no entanto, esse aumento se deve ao menor número de células totais que foram incubadas com VE-CDDP "pré" (Figura 14.B). Baseado na massa proteica para quantificar as VEs, o gráfico apresentado na figura 14.B mostra que a incorporação de VEs acompanha um gradiente de massa proteica oferecido às células. Portanto, podemos inferir que quanto maior a quantidade de VEs oferecidas, maior o percentual de células que incorporam VEs. 


\subsection{Análise do perfil diferencial de VEs obtidas por diferentes tratamentos}

Para avaliar se o tratamento com as drogas CDDP ou TMZ geram VEs com diferentes características, células de melanoma B16-F10 foram tratadas com CDDP ou TMZ nas concentrações e tempo determinados anteriormente. Foram geradas VEs oriundas de células tratadas com CDDP (VE-CDDP) e VEs oriundas do controle de CDDP (VE-PBS) e VEs oriundas de células tratadas com TMZ (VE-TMZ) e VEs oriundas do controle de TMZ (VE-DMSO). As VEs foram isoladas através de sucessivas centrifugações e o precipitado resultante foi utilizado para a análise de rastreamento de nanopartículas e a quantificação de VEs.
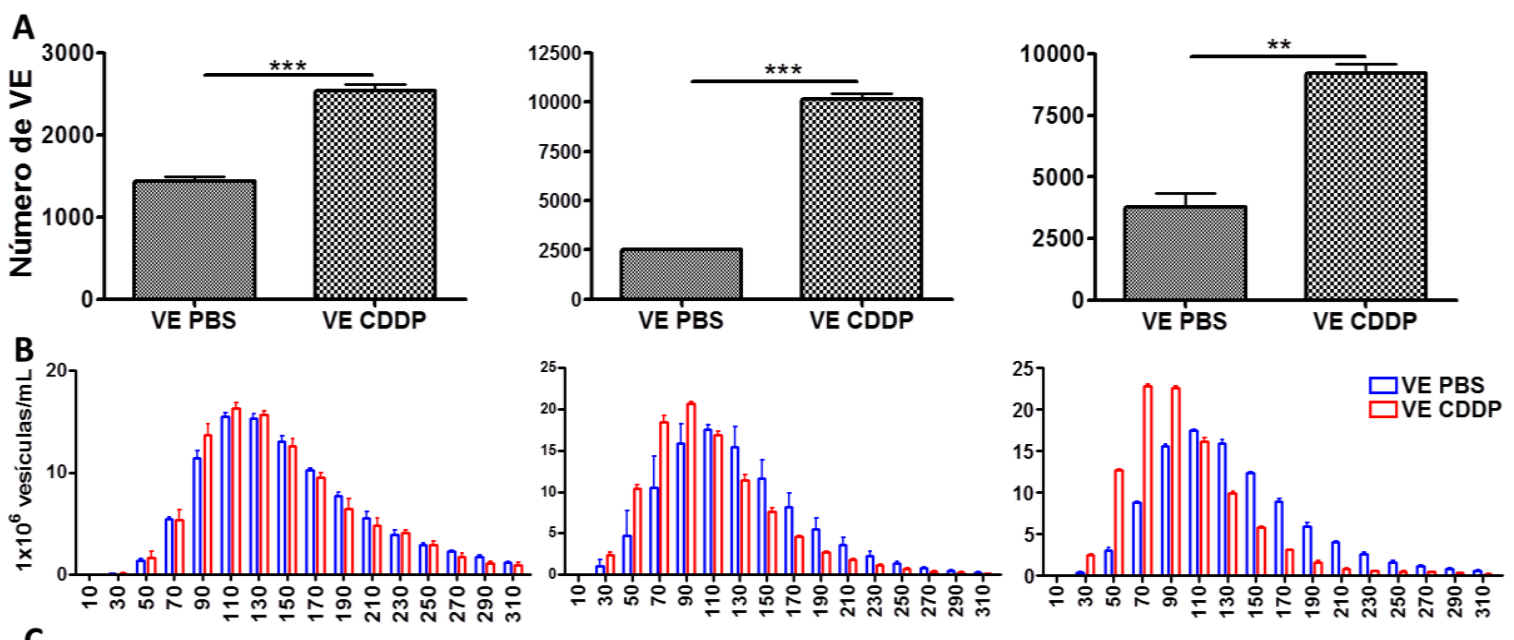
C
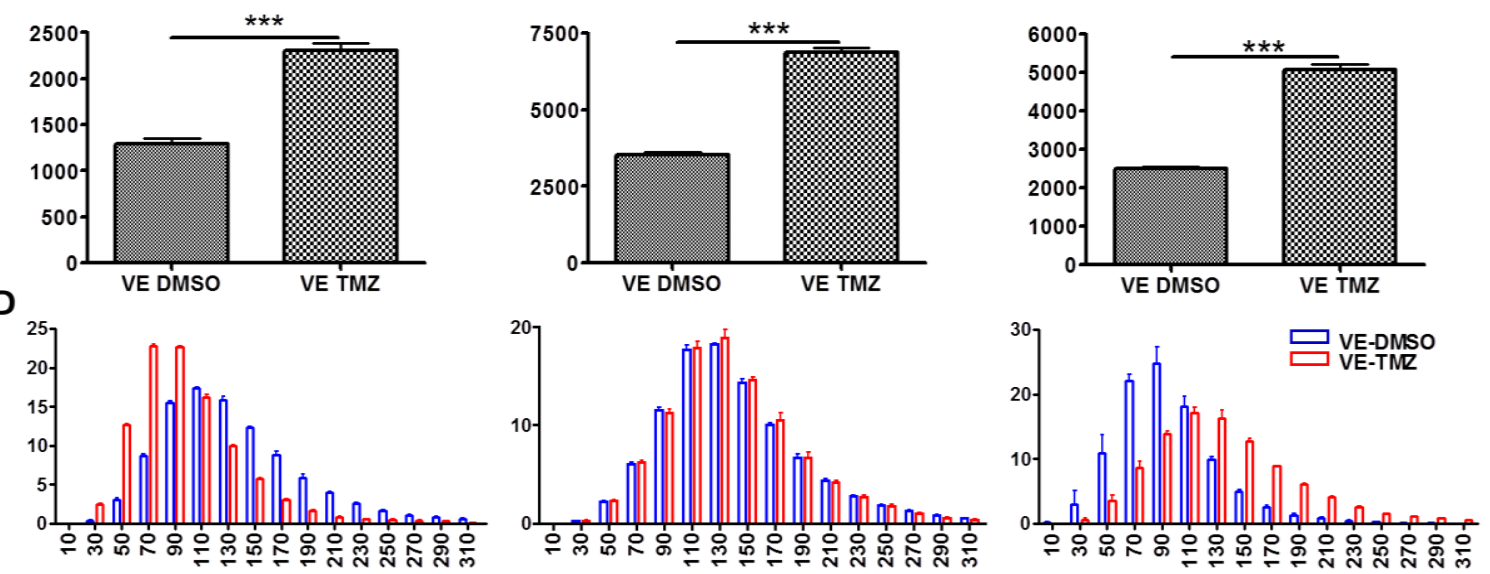

Figura 15: Quantificação e análise de rastreamento de partículas de VEs oriundas de células tratadas com CDDP e TMZ. A) Número de vesículas liberadas por células tratadas com CDDP. B) Perfil do diâmetro em nanômetros das VEs mostrando VE-CDDP e seu controle VE-PBS. C) Número de vesículas liberadas por células tratadas com TMZ. D) Perfil do diâmetro em nanômetros das VEs mostrando VE-TMZ e seu controle VE-DMSO. 
A quantificação de VEs liberadas por célula, apresentadas nas figuras 15.A e 15.C mostram que células tratadas com CDDP ou TMZ liberam mais VEs quando comparadas as células controles (PBS ou DMSO). A análise de rastreamento de nanopartículas apresentada nas figuras 15.B e 15.D mostram que os diâmetros das VEs se mantêm menores que $130 \mathrm{~nm}$. Esses resultados se repetiram em 6 análises para a droga CDDP e 7 análises para a droga TMZ apresentado na figura 16. As VEs isoladas em diferentes datas apresentam perfis de diâmetros semelhantes, indicando que o tratamento com a CDDP ou TMZ podem gerar VEs em maior quantidade quando comparadas aos seus controles, mas mantendo um intervalo de diâmetro entre 70 a 130 nm. Esses resultados sugerem que mesmo que a liberação de VEs por células seja inconstante, podendo ser influenciada por mudanças de $\mathrm{pH}$ do meio de cultura ou pela confluência celular na placa de cultura, a metodologia do isolamento de VEs tem se mostrado adequada e para obtenção de VEs entre 70 a $130 \mathrm{~nm}$.
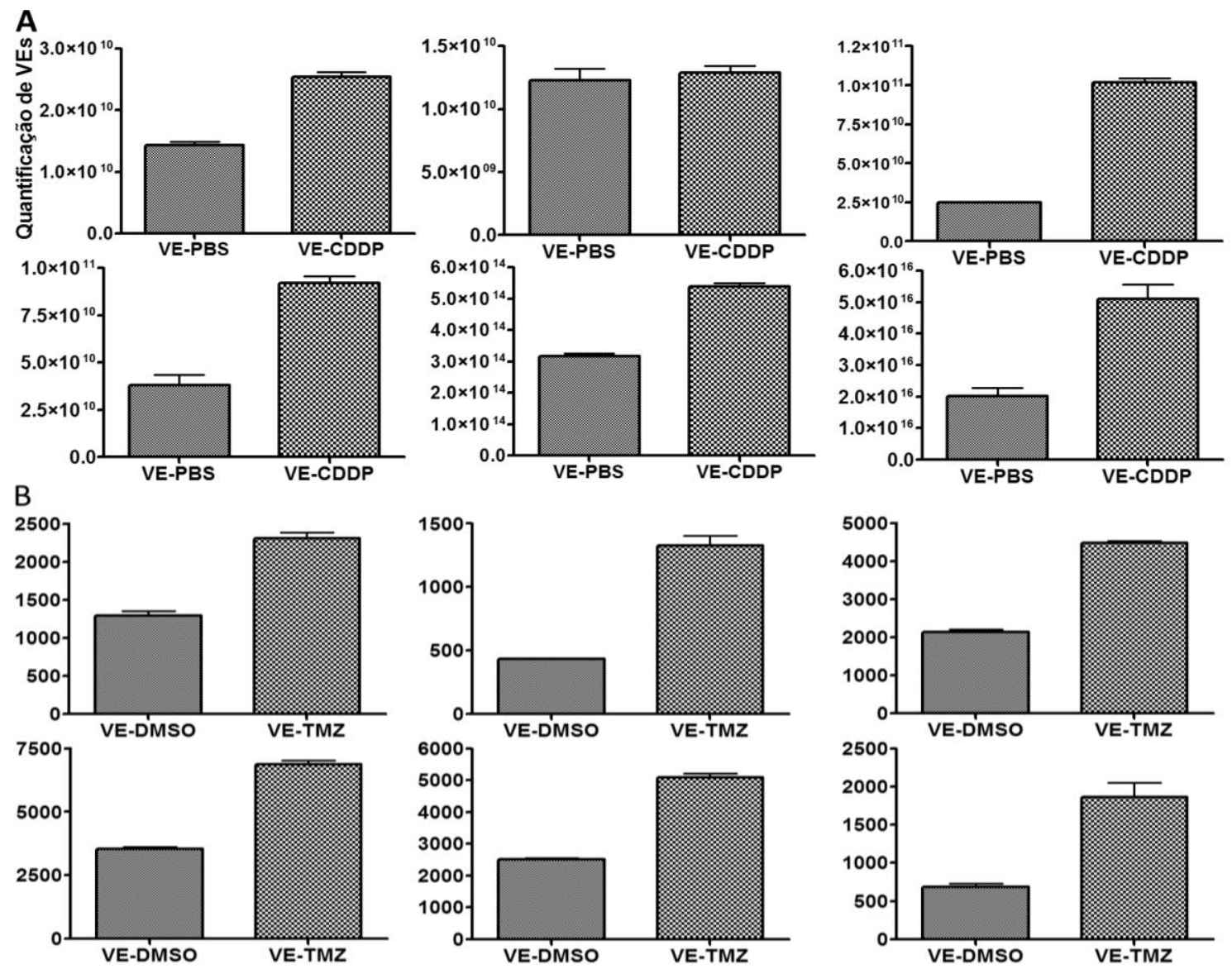

Figura 16: Quantificação de VEs liberadas por célula. A) Razão de VEs por número de células tratadas com CDDP. B) Razão de VEs por número de células tratadas com TMZ. 


\subsection{Análise das respostas celulares conferidos por VEs resultantes de diferentes tratamentos}

\subsubsection{Avaliação da atividade de VEs oriundas de células tratadas com CDDP ou TMZ em B16-F10}

Para determinar os fenômenos celulares conferidos, em células tumorais in vitro, por VEs oriundas de células tratadas com quimioterápicos, foram realizados ensaios clonogênico para avaliar se essas VEs oferecem um fenômeno de sobrevivência celular a longo prazo e análise de incorporação de iodeto de propídeo para avaliar a citotoxicidade das VEs. As células foram tratadas com as drogas CDDP ou TMZ, juntamente com VEs oriundas de células tratadas com a mesma droga, VE-CDDP ou VE-TMZ, ou com os respectivos controles, VE-PBS ou VE-DMSO.
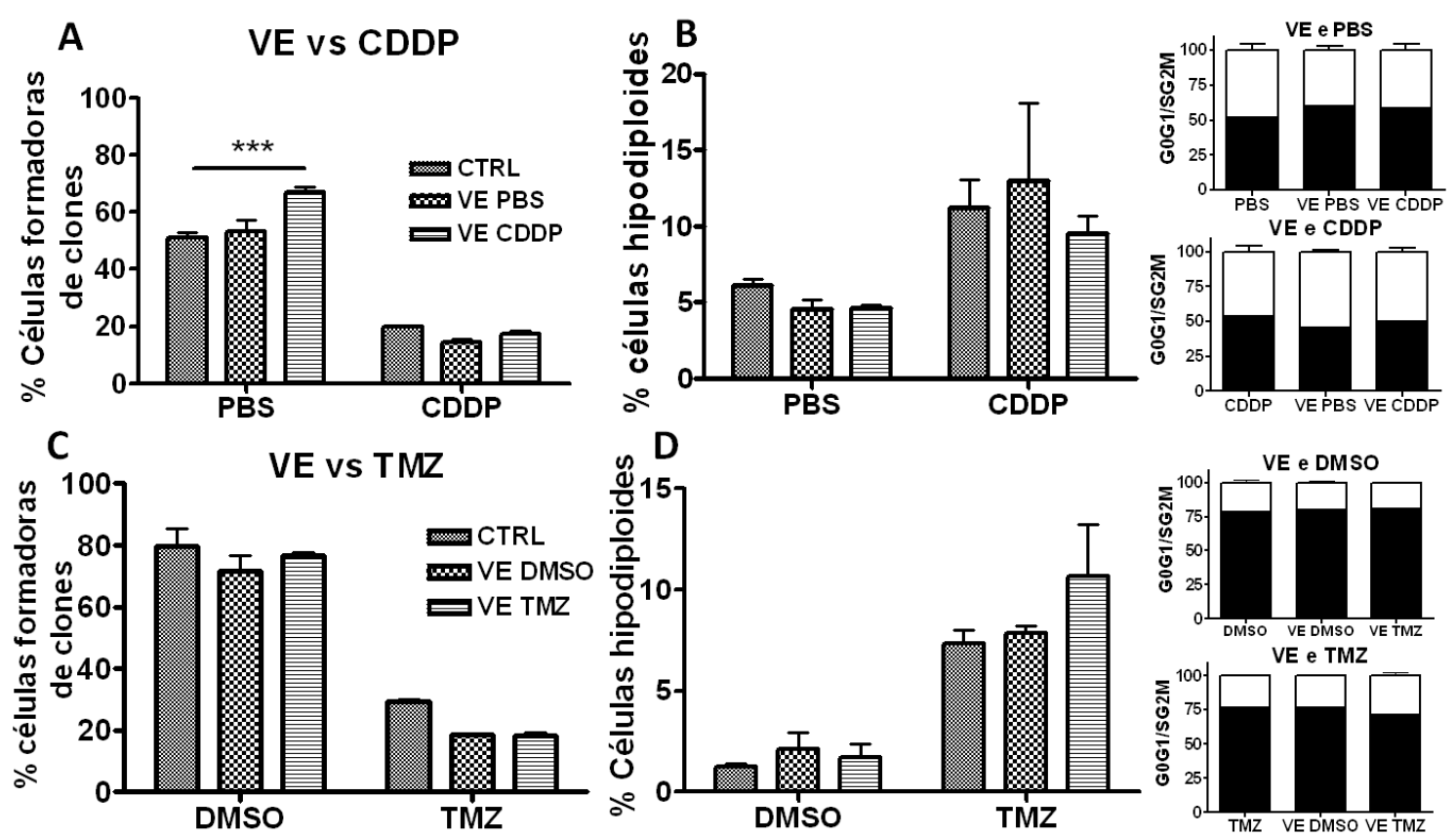

Figura 17: Resposta celular após o tratamento com VEs. A) Análise de formação de clones de células tratadas com VEs e CDDP. B) Morte e fase do ciclo celular de células tratadas com VEs e CDDP. C) Análise de formação de clones de células tratadas com VEs e TMZ. D) Morte e fase do ciclo celular de células tratadas com VEs e TMZ.

A análise de formação de colônias foi realizada tratando as células com 2,5 $\mu \mathrm{M}$ de CDDP na presença de VEs (VE-CDDP) ou o seu controle (VE-PBS), na quantidade de $1 \times 10^{9}$ durante 24 horas. Foi utilizado $2,5 \mu \mathrm{M}$ da droga pois a concentração anteriormente estabelecida (25 $\mu \mathrm{M})$ incapacitou as células de 
gerarem clones. Em paralelo com esse experimento, células B16-F10 foram tratadas com $360 \mu \mathrm{M}$ de TMZ em conjunto com VEs oriundas de células tratadas com a mesma droga (VE-TMZ) ou o seu controle (VE-DMSO), mantivemos a quantidade de $1 \times 10^{9} \mathrm{VEs}$, mas tratando durante 72 horas, pois esse é o tempo de tratamento padronizado para a droga TMZ

O resultado apresentado na figura 17.A mostra que células tratadas com VE-CDDP formam mais clones que células tratadas com VE-PBS ou células que não receberam nenhuma VEs. Já o tratamento com a CDDP juntamente com as VEs (VE-PBS ou VE-CDDP) não mostra diferença significativa na formação de clones. Portanto, podemos inferir que as VE-CDDP conferem um fenômeno de sobrevivência para as células tumorais, mas na vigência da droga, em conjunto com as VEs, este efeito não ocorre. Esse resultado se repetiu em 2 de 3 análises (apresentado na figura 18.A), sugerindo que as VEs oriundas de tratamento com CDDP podem conferir fenômeno de sobrevivência em células não expostas anteriormente à droga.

O resultado apresentado na figura 17.C mostra que não existe diferença significativa na formação de clones de células tratadas com VE-TMZ ou VEDMSO. Portanto, inferimos que as VEs oriundas de células tratadas com a TMZ não conferem capacidade de sobrevivência em células tumorais. Esse resultado se repetiu em 2 de 3 análises. No entanto, o resultado apresentado na figura 18.B mostra que células tratadas com VE-TMZ formam mais clones que células tratadas com VE-DMSO. Além disso, células tratadas com TMZ na presença de VE-TMZ ou VE-DMSO formaram mais clones quando comparado às células tratadas com TMZ na ausência de VEs. Esse resultado controverso sugere que as VEs oriundas de células tratadas com a TMZ podem oferecem um efeito de sobrevivência para as células tumorais, uma vez que foi utilizado o mesmo lote de VEs, mas para o experimento da figura suplementar, as VEs estavam recém-isoladas. 


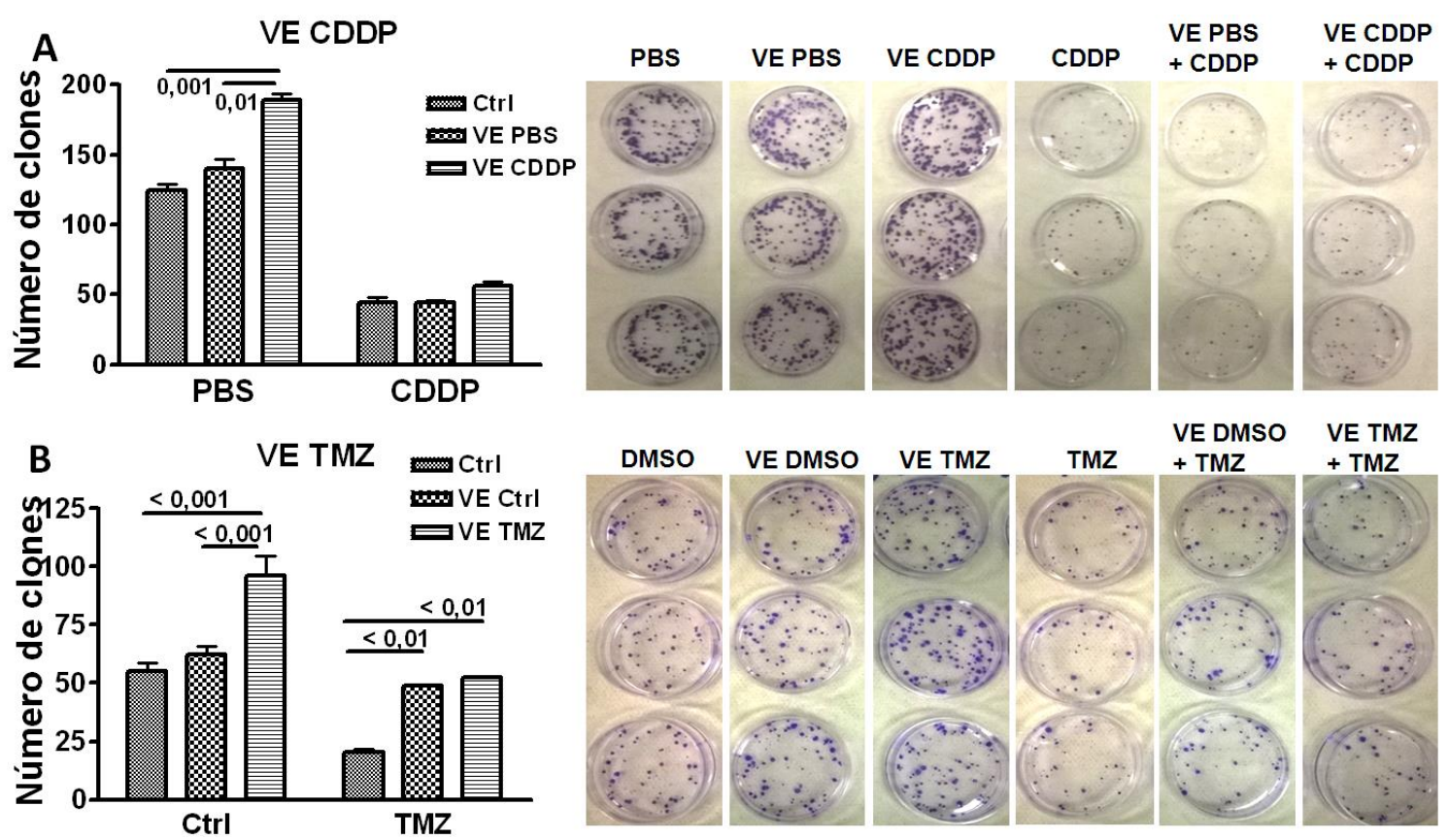

Figura 18: Resposta celular após o tratamento com VEs. A) Análise de formação de clones de células tratadas com VEs e CDDP. B) Análise de formação de clones de células tratadas com VEs e TMZ.

As VEs oriundas de células tratadas com CDDP ou TMZ não são citotóxicas para as células tumorais (figura 17.B e 18.D), ou seja, não existe diferença significativa no percentual de células hipodiploides no tratamento com VEs obtidas de células tratadas com CDDP ou TMZ, ou os controles PBS e DMSO. Não existe diferença no percentual da população celular na fase SG2M em todos os casos. Também não existe diferença no percentual de células hipodiploides no tratamento combinado VEs com as drogas, assim como não existe diferença no percentual da população na fase SG2M. Esses resultados sugerem que essas VEs não participam da sensibilização à morte de células tumorais causadas por CDDP ou TMZ.

\subsubsection{Avaliação da atividade de VEs oriundas de células tratadas com CDDP ou TMZ em células tumorais in vivo}

Para avaliar o possível envolvimento das VEs oriundas de células tratadas com a TMZ no crescimento tumoral, as células B16-F10 foram incubadas com VEs oriundas de células tratadas com as drogas CDDP (VECDDP) ou TMZ (VE-TMZ) ou com os controles (VE-PBS ou VE-DMSO), em seguida inoculadas. O surgimento e o crescimento do tumor foram observados e mensurados diariamente. 

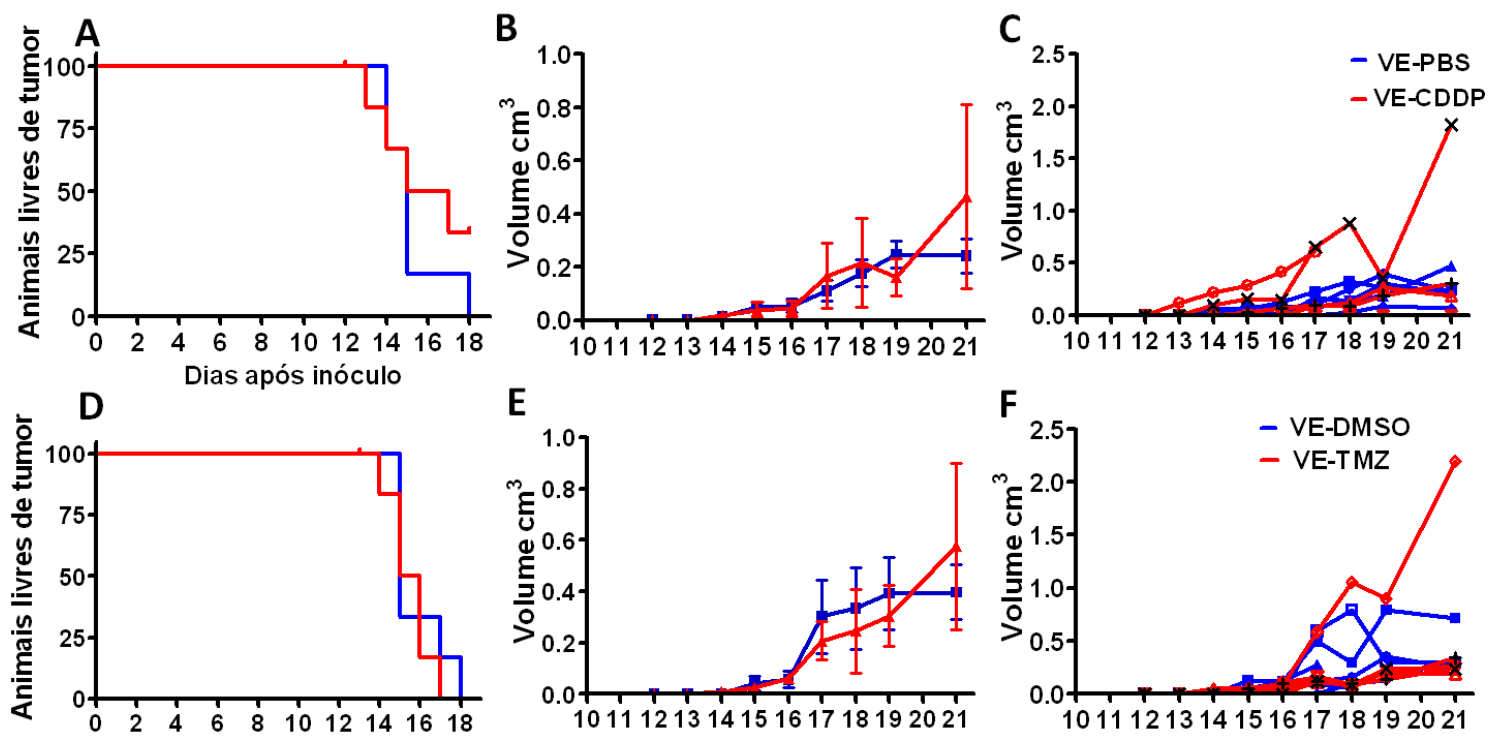

Figura 19: Atividade das VEs oriundas de células tratadas com CDDP ou TMZ no crescimento tumoral. A) Curva Kaplan Meier de surgimento mensurável do tumor de animais inoculados com células B16-F10 expostas à VE-CDDP. B) Curva de crescimento tumoral de animais inoculados com células B16-F10 expostas à VE-CDDP. C) Curva de crescimento tumoral individual de animais inoculados com células B16-F10 expostas à VE-CDDP. D) Curva Kaplan Meier de surgimento mensurável do tumor de animais inoculados com células B16-F10 expostas à VE-TMZ. E) Curva de crescimento tumoral de animais inoculados com células B16-F10 expostas à VE-TMZ. F) Curva de crescimento tumoral individual de animais inoculados com células B16-F10 expostas à VE-TMZ.

As curvas Kaplan Meier apresentados na figura 19.A e 19.D mostram o tempo de surgimento dos tumores. O resultado sugere que células tumorais pré-incubadas com VE-CDDP ou VE-TMZ apresentam surgimento precoce, quando comparadas ao surgimento do tumor com células pré-tratadas com VEPBS ou VE-DMSO. Já as curvas de crescimento tumoral (figura 19.B e 19.E) mostram que células tumorais pré-incubadas com VE-CDDP ou VE-TMZ apresentam maior crescimento, porém, não existe diferença significativa entre esses grupos.

O gráfico apresentado na figura 18.C mostra que apenas 2 animais entre os 6, apresentaram maior crescimento. E no grupo de animais inoculados com células expostas à VE-TMZ, apenas um animal apresenta maior crescimento. Além disso, no grupo VE-DMSO, 2 animais entre 6 apresentam o crescimento acelerado.

Esses resultados são inconclusivos, uma vez que os experimentos foram pilotos para determinar o protocolo em que possibilite observar a ação das VEs 
no tumor. Contudo, podemos inferir que a linhagem B16-F10 não é o melhor modelo para esse objetivo, pois, essa linhagem celular apresenta um rápido crescimento in vivo em um modelo animal que apresenta um crescimento tumoral heterogêneo nessa linhagem. 


\section{DISCUSSÃO}

Em nosso estudo, observamos um aumento na quantidade de VEs liberadas por células tumorais tratadas com CDDP ou TMZ. Além disso, observamos uma interação entre as células tumorais através das VEs, as quais podem induzir proteção em células de melanoma.

A avaliação da toxicidade das drogas (CDDP ou TMZ) mostrou que as concentrações de 25 e $50 \mu \mathrm{M}$ de cisplatina são citotóxicas para as células B16F10. Alemón-Medina mostrou em 2011 que 33 e $66 \mu \mathrm{M}$ de CDDP diminui a taxa de proliferação celular na linhagem B16 [Alemón-Medina $R$ et al, 2011]. Observamos também que a concentração de 27 e $81 \mu M$ de TMZ não apresenta toxicidade às células, mas a concentração de $360 \mu \mathrm{M}$ de temozolomida é citotostática para as células B16-F10. Em 2007, Mhaidat mostrou que a temozolomida induz a senescência celular em células de melanoma. Ele observou que não há aumento no percentual de células hipodiploides, mas aumenta o percentual da população celular na fase G2M, corroborando o nosso resultado. Mhaidat também mostrou que as células tratadas com TMZ apresentam características morfológicas de células em senescência e aumento na atividade da enzima SA $\beta$-Gal (beta-galactosidase associada à senescência) [Mhaidat NM et al, 2007].

Os tratamentos com CDDP ou TMZ aumentaram a quantidade de VEs liberadas por células tumorais. Os resultados obtidos na análise do perfil diferencial de VEs obtidas por diferentes tratamentos mostram que as células tratadas com CDDP ou TMZ liberam maior número de VEs quando comparadas ao seu controle. Mas a liberação de VEs por células tratadas ou não tratadas mantem-se entre 70 a $130 \mathrm{~nm}$ de diâmetro. Banizs (2014) e Figliolini (2014) mostraram que VEs oriundas de células endoteliais [Banizs AB et al, 2014] e pancreáticas [Figliolini $F$ et al, 2014] apresentam perfis característicos da sua célula de origem.

Um estudo realizado por Li publicado em 2012 mostrou o efeito de drogas antitumorais em células da linhagem de carcinoma hepatocelular humano, verificando que essas células secretam VEs constitutivamente, mas o tratamento com quimioterápicos aumenta consideravelmente a liberação de VEs [Lv LH et al, 2012]. Em outro estudo, Federic observou um aumento da 
liberação de exossomos em células de melanoma tratadas com CDDP. Ele atribuiu esse fenômeno ao mecanismo de quimiorresistência à droga, mostrando que as células liberam VEs contendo CDDP em seu interior [Federici C et al, 2014].

Avaliamos também os fenômenos celulares conferidos por VEs resultantes de tratamentos com CDDP ou TMZ. Observamos que as células que receberam VEs oriundas de células tratadas com CDDP ou TMZ aumentaram a capacidade de formar clones quando comparadas aos controles sem VEs. Em 2013, Panagopoulos observou que as células de câncer de próstata (linhagem DU145), consideradas não resistentes à camptotecina, adquiriram resistência à droga após serem expostas às VEs liberadas por células da linhagem PrECs, consideradas resistentes a essa droga [26]. Nossos resultados sugerem que as células que receberam a combinação de tratamento com VEs oriundas do tratamento com CDDP, podem aumentar a capacidade das células, não expostas à droga, de formar clones. Contudo, há necessidade de maior estudo sobre a transferência de fenótipos de sobrevivência, que células expostas à droga podem transferir à outra célula, não exposta a droga.

A avaliação do fenômeno de sobrevivência celular in vivo conferido por VEs oriundas de diferentes tratamentos mostra ser inconclusiva. Nossa hipótese foi baseada nos trabalhos de Bachi et al (2009), que observou aumento no crescimento tumoral de células de melanoma, inoculadas em doses subtumorigênicas juntamente com grande quantidade de células apoptóticas [Bachi AL et al, 2009], e, Ferracini et al (2013) que observou o mesmo fenômeno e associou as moléculas lipídicas e resposta inflamatória local como principais promotores dessa ação [Ferracini $M$ et al, 2013]. Em ambos os trabalhos foram utilizados fragmentos de células apoptóticas, que entre esse material podem conter VEs. Para confirmar que as VEs fazem parte da adaptação tumoral conferindo fenômenos de sobrevivência celular in vivo, é necessário avaliar em outros modelos, como linhagens celulares mais lentas em modelos animais que não apresentem crescimento tumoral heterogêneo. 


\subsection{Considerações finais}

Os mecanismos e vias envolvidos no fenômeno de sobrevivência celular adquirido após a exposição das células de melanoma às VEs oriundas de células tratadas com quimioterápicos precisam ser melhores investigados.

\section{CONCLUSÃO}

Conclui-se que a metodologia do isolamento de VEs é eficiente, garantindo a obtenção de VEs entre 70 a 130 nm de diâmetro. Após tratar as células de melanoma com VEs oriundas de células tratadas com quimioterápicos, observamos que as VEs oriundas de células de melanoma não participam inicialmente da sensibilização à morte de células tumorais causada pelas mesmas drogas, mas a longo prazo, as células tratadas com VEs oriundas de tratamento com TMZ apresentam maior capacidade de sobrevivência in vitro. In vivo, não é possível concluir que as VEs oriundas de células tumorais tratadas com CDDP ou TMZ aumentam a capacidade de sobrevivência de células de melanoma, uma vez que a linhagem celular utilizada para os experimentos apresenta crescimento rápido em um modelo animal que apresenta o crescimento tumoral heterogêneo. Para confirmar a hipótese de que as células tumorais favorecem a sobrevivência através da liberação de VEs, é necessário utilizar outros modelos experimentais. A interação das VEs com outras células do microambiente tumoral, como macrófagos e fibroblastos, e estudos sobre as moléculas que são carregadas por VEs, são necessárias para compreender a importância dessas estruturas na biologia celular do câncer. 


\section{Referências bibliográficas}

Alemón-Medina R, Bravo-Gómez ME, Gracia-Mora MI, Ruiz-Azuara L. Comparison between the antiproliferative effect and intracellular glutathione depletion induced by Casiopeínallgly and cisplatin in murine melanoma B16 cells. Toxicol In Vitro. 2011, Jun;25(4):868-73.

Bachi AL, Kim FJ, Nonogaki S, Carneiro CR, Lopes JD, Jasiulionis MG, Correa M. Leukotriene B4 creates a favorable microenvironment for murine melanoma growth. Mol Cancer Res. 2009, Sep;7(9):1417-24.

Bajetta E, Del Vecchio M, Bernard-Marty C, Vitali M, Buzzoni R, Rixe O, Nova P, Aglione S, Taillibert S, Khayat D. Metastatic melanoma: chemotherapy. Semin Oncol. 2002 Oct;29(5):427-45.

Baj-Krzyworzeka M, Szatanek R, Weglarczyk K, Baran J, Urbanowicz B, Brański P, Ratajczak MZ, Zembala M. Tumour-derived microvesicles carry several surface determinants and mRNA of tumour cells and transfer some of these determinants to monocytes. Cancerlmmunollmmunother 2006, 55: 808818

Baj-Krzyworzeka M, Weglarczyk K, Mytar B, Szatanek R, Baran J, Zembala M. Tumour-derived microvesicles contain interleukin-8 and modulate production of chemokines by human monocytes. Anticancerresearch 2011, 31: 1329-1336

Banizs AB, Huang T, Dryden K, Berr SS, Stone JR, Nakamoto RK, Shi W, He J. In vitro evaluation of endothelial exosomes as carriers for small interfering ribonucleic acid delivery. Int J Nanomedicine. 2014, Sep3;9:4223-30.

Bertolotto C. Melanoma: From Melanocyte to Genetic Alterations and Clinical Options. Scientifica 2013, 12.2013;2013:635203.

Bhatia S, Tykodi SS, Thompson JA. Treatment of metastatic melanoma: na overview. Oncology (Williston Park). 2009 May;23(6):488-96.

deVrij J, Maas SL, Kwappenberg KM, Schnoor R, Kleijn A, Dekker L, Luider TM, de Witte LD, Litjens M, van Strien ME, Hol EM, Kroonen J, Robe PA, Lamfers ML, Schilham MW, Broekman ML. Glioblastoma-derived extracellular vesicles modify the phenotype of monocytic cells. Int $\mathrm{J}$ Cancer. 2015, Oct1;137(7):1630-42.

Dunnebacke TH, Levinthal JD, Williams RC. Entryandreleaseofpoliovirus as observed by electron microscopy of cultured cells. J Virol. 1969, Oct4(4):50513.

Fader CM, Aguilera MO, Colombo MI. ATP is released from autophagic vesicles to the extracellular space in a VAMP7-dependent manner. Autophagy. 2012, Dec;8(12):1741-56. 
Fan $\mathrm{CH}$, Liu WL, Cao H, Wen C, Chen L, Jiang G. O6-methylguanine DNA methyltransferase as a promising target for the treatment of temozolomideresistant gliomas. Cell Death Dis. 2013 Oct 24;4:e876.

Fawcett DW. Electron microscope observations on intracellular virus-like particles associated with the cells of the Lucké renal adenocarcinoma. J BiophysBiochemCytol. 1956, Nov25;2(6):725-41 .

Federici C, Petrucci F, Caimi S, Cesolini A, Logozzi M, Borghi M, D'llio S, Lugini L, Violante N, Azzarito T, Majorani C, Brambilla D, Fais S. Exosome release and low $\mathrm{pH}$ belong to a framework of resistance of human melanoma cells to cisplatin. PLoSOne. 2014, Feb 6;9(2):e88193.

Ferracini M, Rios FJ, Pecenin M, Jancar S. Clearance of apoptotic cells by macrophages induces regulatory phenotype and involves stimulation of CD36 and platelet-activating factor receptor. MediatorsInflamm. 2013, 2013:950273

Figliolini F, Cantaluppi V, De Lena M, Beltramo S, Romagnoli R, Salizzoni M, Melzi R, Nano R, Piemonti L, Tetta C, Biancone L, Camussi G. Isolation, characterization and potential role in beta cell-endothelium cross-talk of extracellular vesicles releasedfrom human pancreatic islets. PLoSOne. 2014, Jul 16;9(7):e102521.

Francisco G, Otake A H, Saito R F, ChammasR. Biologia Molecular dos Melanomas. In: Paulo Marcelo GehmHoff; Roger Chammas; Artur Katz; Vicente Odone Filho; YanaSarkisNovis. (Org.). Tratado de Oncologia. 1ed.São Paulo: Editora Atheneu, 2013, volume. 1, 2325-2342.

György B, Szabó TG, Pásztói M, Pál Z, Misják P, Aradi B, László V, Pállinger E, Pap E, Kittel A, Nagy G, Falus A, Buzás El. Membrane vesicles, current state-of-the-art: emerging role of extracellular vesicles. Cell Mol Life Sci. 2011, Aug68(16):2667-88.

Hedlund M, Nagaeva O, Kargl D, Baranov V, Mincheva-Nilsson L. Thermal- and oxidative stress causes enhanced release of NKG2D ligand-bearing immunosuppressive exosomesin leukemia/lymphoma $T$ and $B$ cells. PLoSOne. 2011, Feb 25;6(2):e16899.

Hood JL, San RS, Wickline SA. Exosomes released by melanoma cells prepare sentinel lymph nodes for tumor metastasis. Cancer Res. 2011, Jun1;71(11):3792-801.

Inal JM, Ansa-Addo EA, Stratton D, Kholia S, Antwi-Baffour SS, Jorfi S, Lange S. Microvesicles in health and disease. ArchlmmunolTherExp. 2012, 60:107121

INCA:

http://www2.inca.gov.br/wps/wcm/connect/tiposdecancer/site/home/pele_melan oma/definicao+ - junho de 2017 
Kawamoto T, Ohga N, Akiyama K, Hirata N, Kitahara S, Maishi N, Osawa T, Yamamoto K, Kondoh M, Shindoh M, Hida Y, Hida K. Tumor-derived microvesicles induce proangiogenic phenotype in endotelial cells via endocytosis. PLoSOne. 2012, 7(3):e34045.

La Porta CA. Mechanism of drug sensitivity and resistance in melanoma. Curr Cancer Drug Targets. 2009 May;9(3):391-7.

Lv LH, Wan YL, Lin Y, Zhang W, Yang M, Li GL, Lin HM, Shang CZ, Chen YJ, and Min J. Anticancer Drugs Cause Release of Exosomes with Heat Shock Proteins from Human Hepatocellular Carcinoma Cells That Elicit Effective Natural Killer Cell Antitumor Responses in Vitro. Journal of biological chemistry 2012, 287.19.

Mandic A, Hansson J, Lind S, SHOSHAN MC. Cisplatin induces endoplasmic reticulum stress and nucleus-independent apoptotic signaling. The JournalofBiologicalChemistry. 2003; 11:9100-9106.

Marton A, Vizler C, Kusz E, Temesfoi V, Szathmary Z, Nagy K, Szegletes Z, Varo G, Siklos L, Katona RL, Tubak V, Howard OM, Duda E, Minarovits J, Nagy $\mathrm{K}$, Buzas K. Melanoma cell-derived exosomes alter macrophage and dendriticcellf unctions in vitro. ImmunolLett. 2012, NovDec148(1):34-8.

Ministério da Saúde, Secretaria de Atenção à Saúde. PORTARIA № 357, DE 8 DE ABRIL DE 2013Aprova as Diretrizes Diagnósticas e Terapêuticas do Melanoma Maligno Cutâneo.http://bvsms.saude.gov.br/bvs/saudelegis/sas/2013/prt0357_08_04_20 13.html Junho de 2017

Munoz JL, Bliss SA, Greco SJ, Ramkissoon SH, Ligon KL, Rameshwar P. Delivery of Functional Anti-miR-9 by Mesenchymal Stem Cell-derived Exosomes to GlioblastomaMultiforme Cells Conferred Chemosensitivity. Mol TherNucleicAcids. 2013, Oct1;2:e126.

Mhaidat NM, Zhang XD, Allen J, Avery-Kiejda KA, Scott RJ and Hersey P; Temozolomide induces senescence but not apoptosis in human melanoma cells; British Journal of Cancer 2007, 971225 - 1233

Onuchic AC, Machado CM, Saito RF, Rios FJ, Jancar S, Chammas R. Expression of PAFR as part of a prosurvival response to chemotherapy: a novel target for combination therapy in melanoma. Mediators Inflamm. 2012;2012:175408.

Panagopoulos K, Cross-Knorr S, Dillard C, Pantazatos D, Del Tatto M, Mills D, Goldstein L, Renzulli J, Quesenberry P, Chatterjee D. Reversal of chemosensitivity and induction of cell malignancy of a nonmalignant prostate cancer cell line uponextracellular vesicle exposure. Mol Cancer. 2013, Oct8;12(1):118. 
Sarkar A, Mitra S, Mehta S, Raices R, Wewers MD. Monocyte derived microvesicles deliver a cell death message via encapsulated caspase-1. PLoSOne. 2009, Sep25;4(9):e7140.

Sloane BF, Rozhin J, Johnson K, Taylor H, Crissman JD, Honn KV. Cathepsin $\mathrm{B}$ : association with plasma membrane in metastatic tumors. ProcNatlAcadSci $U$ S A. 1986, Apr;83(8):2483-7.

Théry C, Amigorena S, Raposo G, Clayton A. Isolation and characterization of exosomes from cell culture supernatantsand biological fluids. CurrProtocCell Biol. 2006, Apr;Chapter 3:Unit 3.22.

Thomas A, Tanaka M, Trepel J, Reinhold WC, Rajapakse VN, Pommier Y. Temozolomide in the Era of Precision Medicine. Cancer Res. 2017 Feb $15 ; 77(4): 823-826$.

van der Vos KE, Abels ER, Zhang X, Lai C, Carrizosa E, Oakley D, Prabhakar S, Mardini O, Crommentuijn MH, Skog J, Krichevsky AM, StemmerRachamimov A, Mempel TR, El Khoury J, Hickman SE, Breakefield XO. Directly visualized glioblastoma-derived extracellular vesicles transfer RNA to microglia/macrophages in thebrain. NeuroOncol. 2016, Jan;18(1):58-69.

Wang D, Lippard SJ. Cellular processing of platinum anticancer drugs. NatureReviews. Drugs Discovery. 2005; 4:307-20.

Zaidi MR, Day CP, Merlino G. From UVs to metastases: modeling melanoma initiation and progression in the mouse. J InvestDermatol. 2008, 128(10):238191 